\title{
Oxygen Activation Switch in the Copper Amine Oxidase of Escherichia coli
}

\author{
Thembaninkosi G. Gaule, ${ }^{\dagger}$ Mark A. Smith, ${ }^{\dagger}$ Katarzyna M. Tych, ${ }^{\dagger \neq}$ Pascale Pirrat, $^{\dagger}$ Chi H. Trinh, ${ }^{\dagger}$
} Arwen R. Pearson, ${ }^{\dagger, \S}$ Peter F. Knowles, ${ }^{\dagger}$ and Michael J. McPherson ${ }^{*}{ }^{\dagger} \odot$

${ }^{\dagger}$ Astbury Centre for Structural Molecular Biology and School of Molecular and Cellular Biology, Faculty of Biological Sciences, University of Leeds, Leeds LS2 9JT, U.K.

${ }^{\ddagger}$ Physik-Department, Lehrstuhl für Biophysik E22, Technische Universität München, D-85748 Garching, Germany

${ }^{\S}$ Hamburg Centre of Ultrafast Imaging and Institute for Nanostructure and Solid State Physics, Universität Hamburg, D-22761 Hamburg, Germany

\section{Supporting Information}

ABSTRACT: Copper amine oxidases (CuAOs) are metalloenzymes that reduce molecular oxygen to hydrogen peroxide during catalytic turnover of primary amines. In addition to $\mathrm{Cu}^{2+}$ in the active site, two peripheral calcium sites, $\sim 32 \AA$ from the active site, have roles in Escherichia coli amine oxidase (ECAO). The buried $\mathrm{Ca}^{2+}$ (Asp533, Leu534, Asp535, Asp678, and Ala679) is essential for full-length protein production, while the surface $\mathrm{Ca}^{2+}$ (Glu573, Tyr667, Asp670, and Glu672) modulates biogenesis of the 2,4,5-
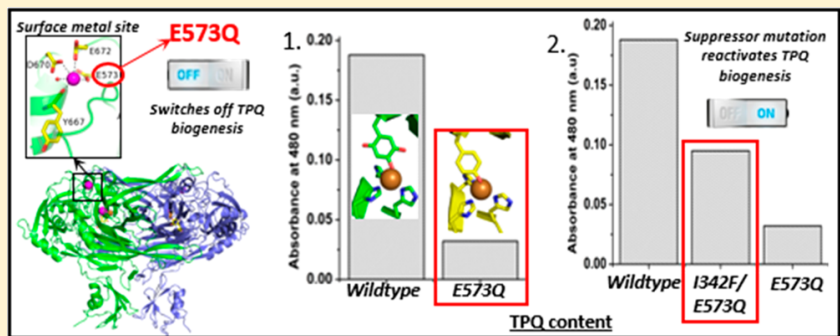
trihydroxyphenylalanine quinone (TPQ) cofactor. The E573Q mutation at the surface site prevents calcium binding and TPQ biogenesis. However, TPQ biogenesis can be restored by a suppressor mutation $(\mathrm{I} 342 \mathrm{~F})$ in the proposed oxygen delivery channel to the active site. While supporting TPQ biogenesis ( $\sim 60 \%$ WTECAO TPQ), I342F/E573Q has almost no amine oxidase activity ( $4.6 \%$ WTECAO activity). To understand how these long-range mutations have major effects on TPQ biogenesis and catalysis, we employed ultraviolet-visible spectroscopy, steady-state kinetics, inhibition assays, and X-ray crystallography. We show that the surface metal site controls the equilibrium (disproportionation) of the $\mathrm{Cu}^{2+}$-substrate reduced TPQ (TPQ ${ }_{\mathrm{AMQ}}$ ) $\mathrm{Cu}^{+}-\mathrm{TPQ}$ semiquinone $\left(\mathrm{TPQ}_{\mathrm{SQ}}\right)$ couple. Removal of the calcium ion from this site by chelation or mutagenesis shifts the equilibrium to $\mathrm{Cu}^{2+}-\mathrm{TPQ}_{\mathrm{AMQ}}$ or destabilizes $\mathrm{Cu}^{+}-\mathrm{TPQ} \mathrm{SQ}$. Crystal structure analysis shows that TPQ biogenesis is stalled at deprotonation in the $\mathrm{Cu}^{2+}$-tyrosinate state. Our findings support WTECAO using the inner sphere electron transfer mechanism for oxygen reduction during catalysis, and while a $\mathrm{Cu}^{+}-$ tyrosyl radical intermediate is not essential for TPQ biogenesis, it is required for efficient biogenesis.

Copt opper amine oxidases (CuAOs) have important roles in many organisms and have been implicated in a number of pathological conditions. ${ }^{1-9}$ All $\mathrm{CuAOs}$ are homodimers that contain a strictly conserved tryrosine that, in the presence of $\mathrm{Cu}^{2+}$ and $\mathrm{O}_{2}$, undergoes autocatalytic posttranslational modification to generate the 2,4,5-trihydroxylphenylalanine quinone (TPQ) cofactor. $^{10-12}$ In addition to the active site $\mathrm{Cu}^{2+}$ binding site, some but not all $\mathrm{CuAOs}$ also contain one or two peripheral metal sites. ${ }^{13} \mathrm{CuAO}$ catalysis proceeds via a classical ping-pong mechanism with two half-reactions, reductive and oxidative (Scheme 1). The reductive halfreaction (Scheme 1, steps 1-3) has been well characterized for a number of $\mathrm{CuAOs}$. $\mathrm{Cu}^{2+}-\mathrm{TPQ}_{\mathrm{Ox}}(1)$ reacts with a primary amine to form a substrate Schiff base $\left(2, \mathrm{TPQ}_{\mathrm{ss}}\right)$. A conserved aspartate residue acts as a catalytic base (Asp383 in ECAO) to facilitate proton abstraction to form the product Schiff base ( 2 $\rightarrow$ 3, $\left.\mathrm{TPQ}_{\mathrm{PSB}}\right)$. Hydrolysis of $\mathrm{TPQ}_{\mathrm{PSB}}$ (3) releases the aldehyde product, generating the aminoquinol (4, $\left.\mathrm{TPQ}_{\mathrm{AMQ}}\right) \cdot{ }^{14-18}$ Studies of the oxidative half-reaction are more challenging, but two mechanisms have been proposed, inner sphere and outer sphere electron transfer mechanisms. ${ }^{19}$ It has been demonstrated that $\mathrm{Cu}^{2+}-\mathrm{TPQ}_{\mathrm{AMQ}}$ (4) exists in equilibrium with $\mathrm{Cu}^{+}-\mathrm{TPQ}_{\mathrm{SQ}}$ (semiquinone) (5). ${ }^{20}$ The equilibrium $(4 \leftrightarrow 5)$ for this interconversion (disproportionation reaction) depends on the enzyme source, $\mathrm{pH}$, and temperature. $^{21,22}$ In the inner sphere electron transfer mechanism, $\mathrm{O}_{2}$ binds $\mathrm{Cu}^{+}$in the $\mathrm{Cu}^{+}-\mathrm{TPQ}_{\mathrm{sQ}}$ couple and is reduced to superoxide $\left(\mathrm{O}_{2}^{\bullet-}\right),{ }^{23-26}$ consistent with the welldocumented physiological redox active role for $\mathrm{Cu}^{2+}$ / $\mathrm{Cu}^{+}{ }^{19,27,28}$ However, in the outer sphere electron transfer mechanism, $\mathrm{O}_{2}$ binds to a hydrophobic pocket proximate to $\mathrm{TPQ}_{\mathrm{AMQ}}$ and is reduced by $\mathrm{TPQ}_{\mathrm{AMQ}}$ to $\mathrm{O}_{2}{ }^{\bullet-29,30}$ Although the first electron transfer to $\mathrm{O}_{2}$ is different in the two mechanisms, ultimately the $\mathrm{Cu}^{2+}$-hydroperoxide and iminoquinone $\left(6, \mathrm{TPQ}_{\mathrm{IMQ}}\right)$ are generated. Hydrolysis of the

Received: June 8, 2018

Revised: August 14, 2018

Published: August 15, 2018 
Scheme 1. Proposed Catalytic Mechanism of CuAO, a Reductive Half-Reaction $(1 \rightarrow 3)$ and an Oxidative Half-Reaction (inner sphere $5 \rightarrow 6$, outer sphere $4 \rightarrow 6$ )

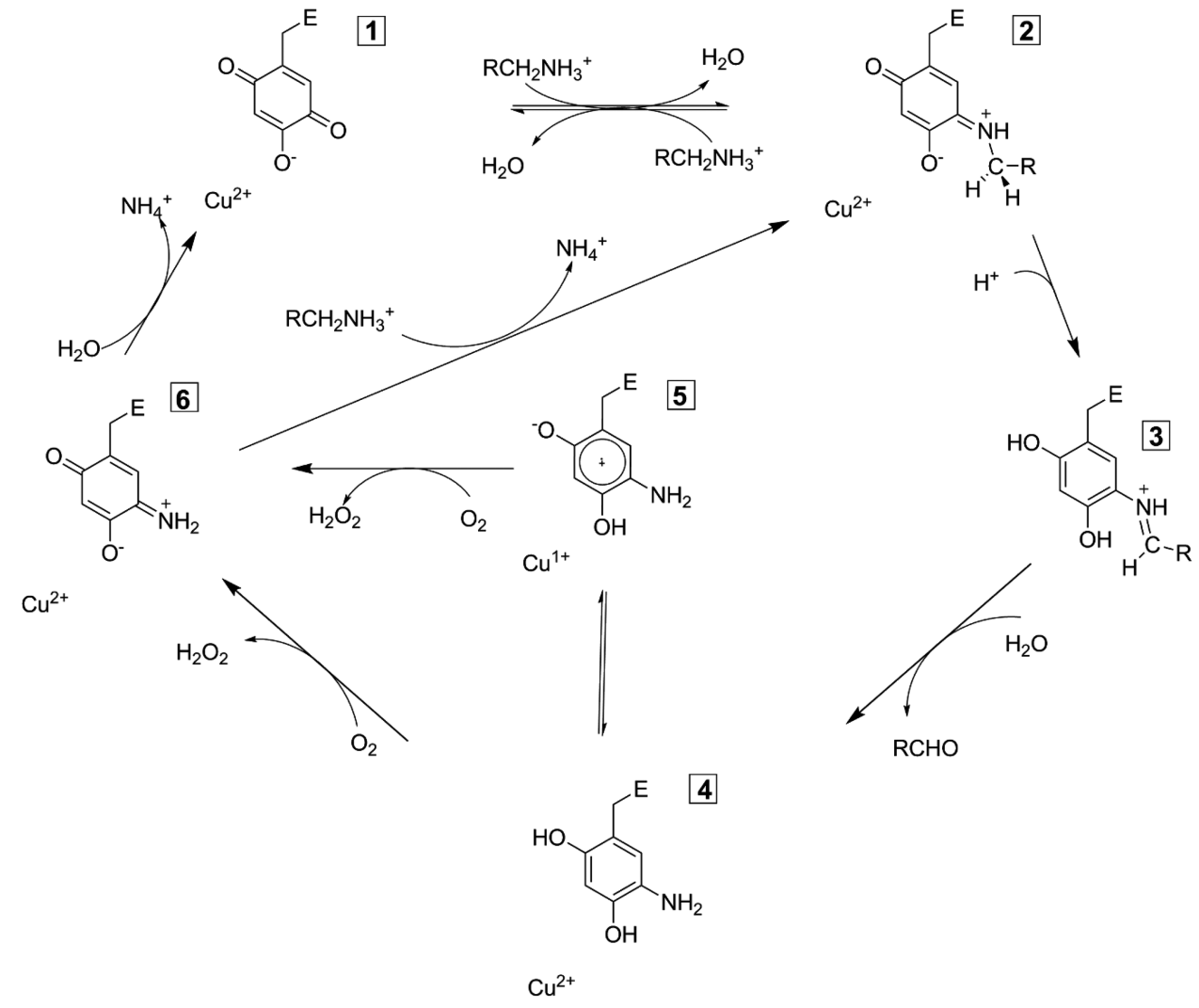

TPQ $\mathrm{IMQ}_{\mathrm{MQ}}$ intermediate releases ammonium and $\mathrm{H}_{2} \mathrm{O}_{2}$ and regenerates state 1 .

The highest turnover rates $\left(k_{\text {cat }}\right)$ are observed in plant CuAOs, which display considerable amounts of $5(\approx 80 \%)$ in the oxidative half-reaction. ${ }^{20,21,23,26}$ Non-plant eukaryotic CuAOs, such as Hansenula polymorpha amine oxidase (HPAO), exhibit the lowest $k_{\text {cat }}$ values and negligible amounts of 5. ${ }^{29,30}$ Experiments performed by Shepard et al. ${ }^{31}$ provided evidence of the redox role of copper in the form of $\mathbf{5}$ in the bacterial Arthrobacter globiformis amine oxidase (AGAO); however, this has not been established in Escherichia coli amine oxidase (ECAO), another bacterial $\mathrm{CuAO}$.

Although the mode of $\mathrm{O}_{2}$ activation differs among $\mathrm{CuAOs, \text {it }}$ occurs in a deeply buried active site. The timely and specific delivery of $\mathrm{O}_{2}$ through the protein matrix to these buried active sites has been an active area of study. ${ }^{32-37}$ Xenon complexes and in silico studies have suggested that molecular oxygen migration follows preferred routes and have identified a conserved $\beta$-sandwich as the likely major pathway for oxygen entry (Figure $1 \mathrm{~b}$, pathway 1$).^{32,38-40}$ Removing $\mathrm{Ca}^{2+}$ from the peripheral sites located at the surface of the protein (Figure 1a) near the opening of the $\beta$-sandwich results in a significant decrease in enzyme activity. ${ }^{13}$ In the work presented here, we show that a single point mutation in ECAO at the surface site interferes with TPQ biogenesis, which can be restored by introducing a second mutation within a hydrophobic channel previously identified as a putative oxygen delivery pathway. We also demonstrate that the buried metal is required for fulllength protein expression.

\section{METHODS}

Mutagenesis, Expression, and Purification of ECAO. Plasmid pKKecao ${ }^{16}$ was used as the template for site-directed mutagenesis using a QuikChange protocol with KOD DNA polymerase $^{41}$ to generate the following single-mutation constructs where each plasmid identifies the mutation introduced: buried metal site, pKKD533N and pKKD678N; surface site, pKKE672K, pKKD670N, and pKKE573Q; and hydrophobic channel, pKKI342F. An additional site-directed mutagenesis step was performed using pKKE573Q as a template to generate the double mutation pKKE573Q/X (where $\mathrm{X}$ is a hydrophobic channel mutation $\mathrm{V} 640 \mathrm{~F} / \mathrm{L} / \mathrm{A}$, I342F/W, V345L/A, or V536L or an active site mutation M699L/A/V or E490Q/I/A). Each variant was confirmed by DNA sequencing.

Wild-type ECAO (WTECAO) and mutational variant proteins were prepared from XL-1 blue cells transformed with the appropriate plasmid. Single colonies were used to inoculate $5 \mathrm{~mL}$ of $2 \mathrm{YT}$ medium with $100 \mu \mathrm{g} / \mathrm{mL}$ disodium carbenicillin and grown at $37{ }^{\circ} \mathrm{C}$ while being shaken at 220 rpm for $16 \mathrm{~h}$. Large scale cultures of $500 \mathrm{~mL}$ of prewarmed $2 \mathrm{YT}$ medium with carbenicillin and $50 \mu \mathrm{M} \mathrm{CuSO}_{4}$ in $2 \mathrm{~L}$ baffled flasks were inoculated with $1 \mathrm{~mL}$ of the starter culture. Following incubation at $37{ }^{\circ} \mathrm{C}$ and $220 \mathrm{rpm}$, when the $\mathrm{OD}_{600}$ reached $0.6-0.8$ isopropyl $\beta$-D-1-thiogalactopyranoside was added to a final concentration of $1 \mathrm{mM}$ and incubation continued for $6 \mathrm{~h}$. Cells were harvested and lysed, and ECAO was purified as previously described. ${ }^{13}$ The gravimetrically derived correction factor of 0.76 was used to determine protein concentration based on its absorbance at $280 \mathrm{~nm}\left(\varepsilon_{280}=2.1 \times\right.$ $\left.10^{5} \mathrm{M}^{-1} \mathrm{~cm}^{-1}\right){ }^{42}$ The molecular masses of WTECAO and 


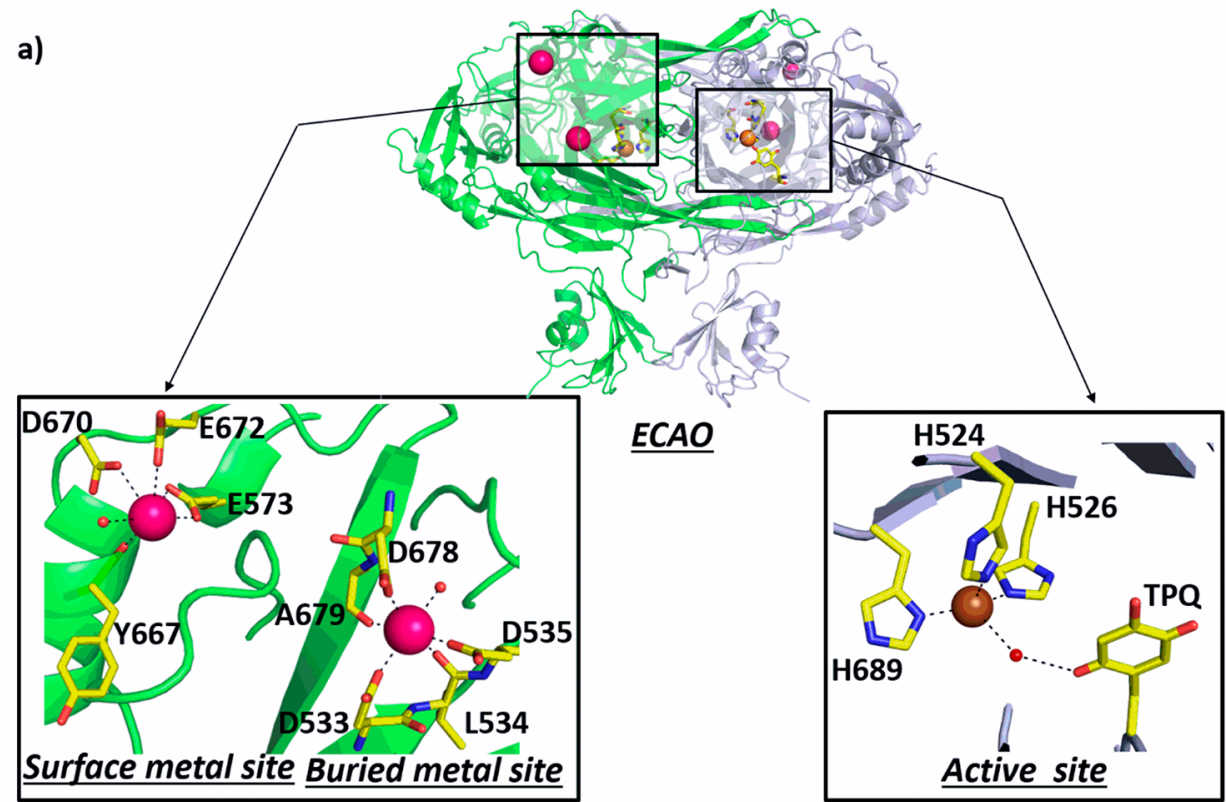

b)

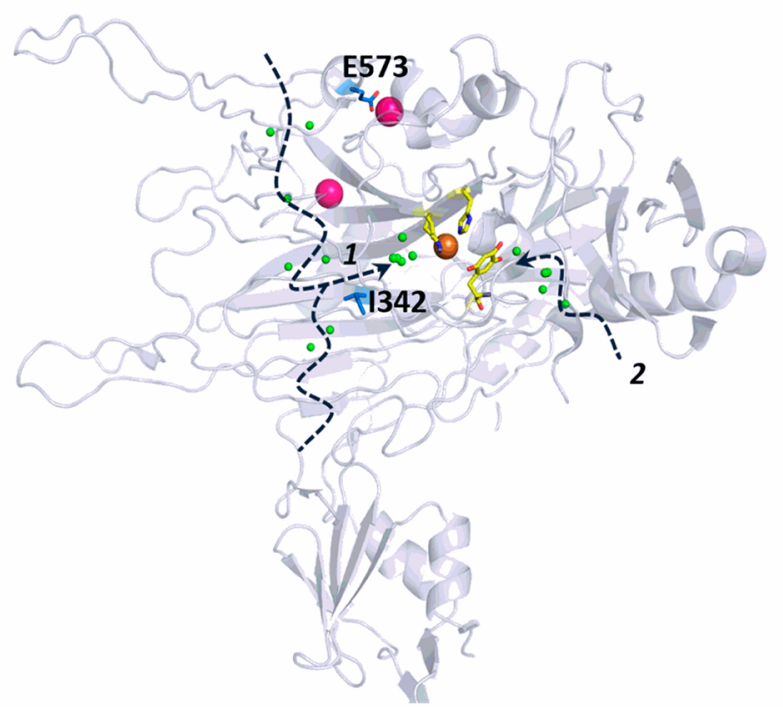

Oxygen pathways

Figure 1. Overview of important structural features of ECAO (Protein Data Bank entry 1DYU). (a) The peripheral surface and buried metal binding sites (left) and the active site (right) are magnified. (b) ECAO monomer showing potential oxygen entry pathways (dashed lines) based on xenon binding sites and residues targeted for mutagenesis (blue sticks). TPQ copper, and calcium ligands are shown as sticks colored by element. Copper and calcium ions are shown as bronze and magenta spheres, respectively. Water molecules are shown as red spheres, and xenons as green spheres.

ECAO variants were determined by mass spectrometry in the Astbury Centre for Structural Molecular Biology of the University of Leeds.

Ultraviolet-Visible (UV-vis) Spectroscopy. A Shimadzu UV2401 PC spectrophotometer equipped with a temperature-controlled cell holder was used to record $\mathrm{CuAO}$ spectra. To detect TPQ spectra were recorded over a range of 280$700 \mathrm{~nm}$. Quantitative analysis of the TPQ content per dimer was achieved by titrating with 2-hydrazinopyridine (2-HP) as previously described. ${ }^{13,43}$ Typically, 6-12 $\mu \mathrm{M}$ enzyme in 100 $\mathrm{mM}$ sodium phosphate ( $\mathrm{pH}$ 7.0) was titrated by stepwise addition of $0.1-1$ molar equivalent of 2-HP. At each titration step, the reaction was allowed to proceed until no further absorbance change was detectable.
Enzyme Activity Assays. Enzyme activity was determined as described previously. ${ }^{13}$ Briefly, $20 \mu \mathrm{L}$ of $0.2 \mu \mathrm{M}$ purified enzyme was added to $980 \mu \mathrm{L}$ of assay buffer [ $100 \mathrm{mM}$ sodium phosphate ( $\mathrm{pH} 7.0$ ), $0.58 \mathrm{mM}$ 2,2'-azinobis(3-ethylbenzothiazoline-6-sulfonic acid) (ABTS), and 15 units $\mathrm{mL}^{-1}$ horseradish peroxidase (HRP)], and the reaction progress was recorded at $410 \mathrm{~nm}$ using a Cary 50 spectrophotometer (Varian). Kinetic parameters, $K_{\mathrm{M} \text { (amine) }}$, and $k_{\mathrm{cat}}$ for $\beta$-phenylethylamine $(\beta$-PEA) were calculated by fitting the initial rates (micromoles per minute per milligram) using Origin Pro 7.5.

To determine $\mathrm{O}_{2}$ kinetic parameters, nitrogen gas was used to displace $\mathrm{O}_{2}$ in buffers, solutions, and enzyme samples. $\mathrm{N}_{2}$ was passed over the headspace present in airtight glass vessels containing $2 \mathrm{~mL}$ of $0.2 \mu \mathrm{M}$ protein. The assay buffer $[100 \mathrm{mM}$ sodium phosphate and $25 \mu \mathrm{M} \beta$-PEA ( $\mathrm{pH} 7.0)]$ was degassed, 
and $\mathrm{N}_{2}$ was bubbled directly into the solution continuously while it was being stirred. A Hansatech Oxygraph system (Hansatech Instruments Ltd.) was assembled, and the electrode was calibrated according to the manufacturer's instructions. Then, $980 \mu \mathrm{L}$ of assay buffer was transferred to the Oxygraph glass reaction vessel from the $\mathrm{N}_{2}$-saturated buffer using an airtight Hamilton syringe and allowed to reach a baseline. Following this, $20 \mu \mathrm{L}$ of $\mathrm{O}_{2}$-free enzyme was added and the rate of $\mathrm{O}_{2}$ consumption was recorded. Varying concentrations of $\mathrm{O}_{2}$ were obtained by mixing different ratios of oxygen-saturated and nitrogen-saturated assay buffer. The data were used to calculate the steady-state kinetic parameters, $K_{\mathrm{M} \text { (oxygen) }}$, and $k_{\text {cat }}$ for $\mathrm{O}_{2}$ by fitting the data to the MichaelisMenten equation using Origin Pro 7.5.

Anaerobic Reduction of ECAO. Solutions were made anaerobic by degassing and passing a steady stream of $\mathrm{N}_{2}$ into them while they were being stirred for $1 \mathrm{~h}$. Protein solutions were not stirred, and anaerobiosis was achieved by passing $\mathrm{N}_{2}$ into the headspace, allowing gas exchange without bubbling directly into the solution. A $240 \mu \mathrm{L}$ aliquot of protein with the active enzyme at a concentration of $100 \mu \mathrm{M}$ (based on TPQ content) was added to a $1 \mathrm{~mL}$ quartz cuvette with a ground glass joint sealed with a rubber septum. The substrate-reduced enzyme was prepared by adding a 5-fold molar excess of anaerobic $\beta$-PEA. Spectra were recorded until no further changes were observed. Subsequently, $\mathrm{O}_{2}$ was allowed to enter the cuvette by diffusion, and spectra were recorded until no further change was observed. To determine the $\mathbf{5}$ content (Scheme 1), a 16-fold molar excess of anaerobic $\mathrm{KCN}$ was added to anaerobically $\beta$-PEA-reduced enzyme and spectra were recorded until no further changes were observed. ${ }^{44}$

The level of $\mathbf{5}$ was calculated using eq 1

$$
\left.\left[\left(A_{467}-A_{480}\right)_{\text {reduced enzyme }} /\left(A_{467}-A_{480}\right)_{\text {reduced enzyme }+\mathrm{CN}^{-}}\right)\right] \times 100
$$

EDTA Treatment. All plasticware was soaked in $100 \mathrm{mM}$ EDTA ( $\mathrm{pH}$ 8.0) for $30 \mathrm{~min}$ and thoroughly rinsed in Chelextreated water. Chelex-treated water and buffers were prepared by passing the solutions through a Chelex-100 (resin, mesh 100-200, Bio-Rad) column. EDTA ( $\mathrm{pH} 7.0$ ) was added to a final concentration 1000-fold higher than that of ECAO and incubated for $2 \mathrm{~h}$. Excess EDTA was removed by three buffer exchange steps using a metal-free centrifugal filter device. Specific activity assays were performed at $25{ }^{\circ} \mathrm{C}$ in assay buffers supplemented with $3 \mathrm{mM} \mathrm{CaCl}_{2}$ and $0.05 \mathrm{mM} \mathrm{CuSO}_{4}$.

X-ray Crystallographic Structure Analysis. Crystals of WTECAO and its variants were grown as previously described. ${ }^{16}$ In brief, the crystals were grown by the sitting drop vapor diffusion method in $100 \mathrm{mM}$ HEPES ( $\mathrm{pH}$ 6.9$7.2)$ and sodium citrate $(1.10-1.35 \mathrm{M})$. A $3-5 \mu \mathrm{L}$ aliquot of a protein sample $(6-12 \mathrm{mg} / \mathrm{mL})$ was mixed with the same volume of mother liquor. Prior to data collection, the drop solution was gradually exchanged with the well solution containing $5 \%(\mathrm{v} / \mathrm{v})$ increments of glycerol to a final concentration of $30-45 \%(\mathrm{v} / \mathrm{v})$ glycerol and subsequently flash-frozen in liquid nitrogen for X-ray data collection. Data were collected at Diamond Light Source (beamline I02). As observed with previous ECAO crystals, the proteins crystallized in space group $P 22_{1} 2_{1} 2_{1}$. The data were processed using $\mathrm{XDS}^{45}$ and SCALA. ${ }^{46}$ The CCP4 suite ${ }^{47}$ was used for further processing, model building, and refinement. $1 \mathrm{DYU},{ }^{16}$ an isomorphous WTECAO structure, was used as a starting model. Refinement and model building were performed using
Refmac5 $5^{48}$ and COOT, ${ }^{49}$ respectively. Rigid body refinement was performed to optimize the orientation of the starting model. COOT was used to build the missing side chains and add the metals and water molecules where appropriate. Successive rounds of positional refinement and rebuilding generated the final model. Details of crystal parameter, data collection, and refinement statistics are listed in Table S1.

\section{RESULTS}

Mutations at the Buried Metal Site. Two residues coordinating the buried $\mathrm{Ca}^{2+}$ were mutated to asparagine (D553N and D678N). No full-length ECAO was detected in periplasmic extracts even when the growth conditions were supplemented with increasing concentrations of $\mathrm{Ca}^{2+}$ and no ECAO enzyme activity could be measured (Figures S1 and S2). These results were unexpected but suggest that $\mathrm{Ca}^{2+}$ in the buried binding site is required for the effective folding and/ or stability of ECAO.

Mutations at the Surface Metal Site. In contrast to the buried metal site, which shows a preference for binding a divalent cation in all CuAOs, with the exception of $H$. polymorpha $\mathrm{CuAO}$ (HPAO), ${ }^{6,41,50-56}$ the surface metal site is promiscuous and binds whatever mono- or divalent cation is available. ${ }^{41}$ Site-directed mutagenesis of residues (E573, D670, and E672) comprising the surface $\mathrm{Ca}^{2+}$ binding site surprisingly resulted in significantly reduced $\mathrm{CuAO}$ activity, even though the expression levels of these mutants were similar to that of WTECAO and the site is some $32 \AA$ from the active site (Figure 2). The reduction in activity followed the trend D670N < E672K « E573Q, with mutation E573Q showing the least activity (Figure 2).

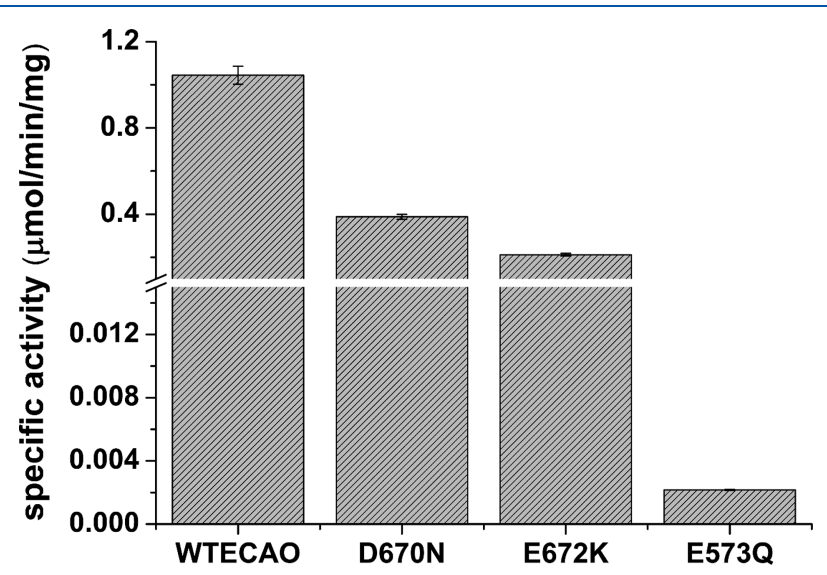

Figure 2. Activity profile of WTECAO and surface metal site mutants (D670N, E672K, and E573Q) where $n=3$.

Effects of Surface Mutation E573Q on TPQ Biogenesis and Catalysis. The E573Q mutant lacked the distinct coloration afforded by the chromophore properties of TPQ. Although ESI-MS suggested the absence of TPQ low levels were detected by UV-vis spectroscopy (Figure 3) and confirmed by 2 -HP titrations $[\sim 16 \%$ of the WTECAO TPQ content (Figure 3, inset)]. Kinetic studies demonstrated a $K_{\mathrm{M} \text { (amine) }}$ of $1.1 \mu \mathrm{M}$ and a $K_{\mathrm{M}\left(\mathrm{O}_{2}\right)}$ of $16.6 \mu \mathrm{M}$, consistent with that of the wild type; however, $\geq 88$-fold reductions in both $k_{\text {cat(amine) }}$ and $k_{\text {cat }\left(\mathrm{O}_{2}\right)}$ were observed (Table 1$)$. Kinetic studies of E573Q demonstrated the observed activity was not due to contamination by wild-type ECAO expression in the host cells, 


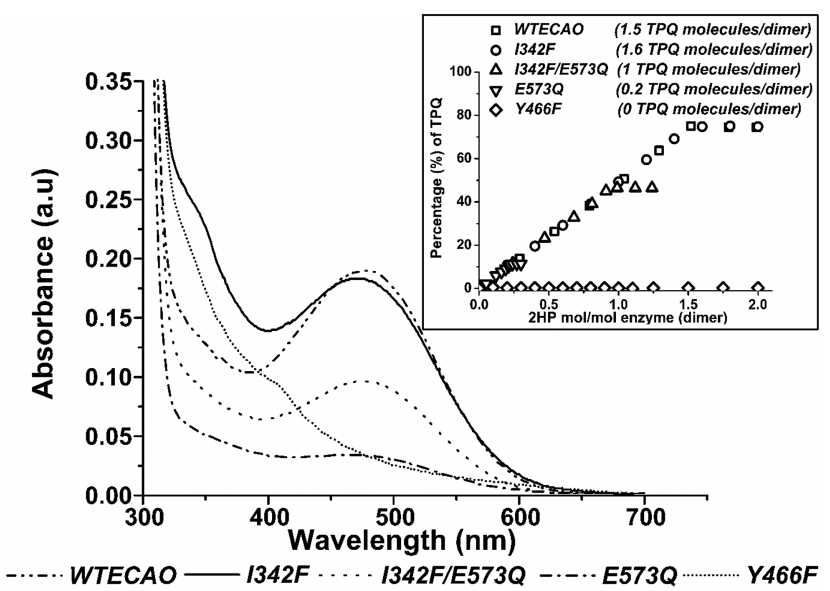

Figure 3. UV-vis spectra of WTECAO, I342F, I342F/E573Q and E573Q at $10 \mathrm{mg} / \mathrm{mL}$ measured in $20 \mathrm{mM}$ Tris ( $\mathrm{pH} 7.0)$. Inset 1 shows the TPQ content in each protein sample measured by titrating TPQ with 2-HP.

as $\mathrm{Y} 466 \mathrm{~F}$, carrying a mutation of the active site tyrosine that is incapable of undergoing processing to form TPQ showed no activity (Figure 3).

Rescue of E573Q by Suppressor Mutations. Attempts to reconstitute activity in the E573Q mutant by saturating with oxygen, incubating at $37{ }^{\circ} \mathrm{C}(24 \mathrm{~h})$, adding $\mathrm{Ca}^{2+}(1 \mathrm{mM})$, prolonging the incubation time $\left(>1\right.$ year at $\left.4{ }^{\circ} \mathrm{C}\right)$, or combinations of these had no effect on TPQ formation or enzyme activity. We therefore attempted to rescue the E573Q phenotype by introducing second site mutations into the active site (M699L/A/V and E490Q/I/A) (Figures S3 and S4) and in the hydrophobic channel proposed to be the route of oxygen entry (V640F/L/A, I342F/W/D, V345L/A/F, V536L/A/F, and Y468A) (Figure S5). ${ }^{41}$ The only mutant that showed any level of rescue of the E573Q phenotype was the I342F mutant. Unfortunately, it did not prove to be possible to produce protein from the I342W or I342D variant.

Effects of a Suppressor Mutation, I342F, on TPQ Biogenesis and Catalysis in E573Q. The I342F mutation resulted in partial suppression of the effects of the E573Q mutation. Unlike E573Q, the double mutant, I342F/E573Q, was pink in color, indicating the presence of substantial TPQ. The UV-vis spectroscopy data (TPQ content and 2HP titrations) showed that the $\mathrm{I} 342 \mathrm{~F}$ mutation partially suppressed the effects of the E573Q mutation, by increasing the TPQ content to $\sim 60 \%$ of the wild-type (WT) TPQ content (Figure 3). Interestingly, however, the kinetic data showed that the turnover rate of $\mathrm{I} 342 \mathrm{~F} / \mathrm{E} 573 \mathrm{Q}$ with respect to both substrates was only $\sim 4 \%$ of that of the WT (Table 1 ). The measured $K_{\mathrm{M}(\text { amine })}(1.4 \mu \mathrm{M})$ and $K_{\mathrm{M}\left(\mathrm{O}_{2}\right)}(20.7 \mu \mathrm{M})$ were consistent with those of WTECAO (Table 1). The I342F single mutant was similar to the wild type with a $K_{\mathrm{M} \text { (amine) }}$ of $1.4 \mu \mathrm{M}$, a $K_{\mathrm{M}\left(\mathrm{O}_{2}\right)}$ of $24.1 \mu \mathrm{M}$, a $k_{\text {cat(amine) }}$ of $16.5 \mathrm{~s}^{-1}$, and a $k_{\text {cat }\left(\mathrm{O}_{2}\right)}$ of $59.6 \mathrm{~s}^{-1}$ (Table 1). The $\mathrm{UV}$-vis spectrum of I342F showed increased absorbance in the $350 \mathrm{~nm}$ region relative to that of the WT and a shift from 480 to $470 \mathrm{~nm}$; together, these changes suggest that there are microenvironmental effects that perturb the electronic structure of the TPQ (Figure 3).

Detecting Differences in the Active Sites of I342F, WT, I342F/E573Q, and E573Q. 2HP titrations determined 1.5 TPQs per dimer in WTECAO, 1.6 TPQs per dimer in I342F, 1 TPQ per dimer in I342F/E573Q and 0.2 TPQ per dimer in E573Q (Figure 3, inset); $1.5 \mathrm{TPQ}$ molecules instead of 2 were detected in WTECAO most probably because of the inefficient processing of the highly conserved tyrosine residue to form TPQ. ${ }^{43,57}$ It is possible that the shoulder at $350 \mathrm{~nm}$ is a result of inefficient processing of the precursor Y466 such that TPQ biogenesis is stalled at the $\mathrm{Cu}$ (II)-tyrosinate intermediate that has a $\lambda_{\max }$ of $350 \mathrm{~nm} .{ }^{58}$ Upon reaction of E573Q and $\mathrm{I} 342 \mathrm{~F} / \mathrm{E} 573 \mathrm{Q}$ with molar equivalents of $2 \mathrm{HP}$, the azo form of adduct $\mathrm{I}$ and adduct $\mathrm{II}^{70}$ were immediately observed as the UV-vis spectra show two peaks at 416 and $520 \mathrm{~nm}$ (Figure 4). ${ }^{59} \mathrm{~A}$ full conversion from the azo form to adduct II was

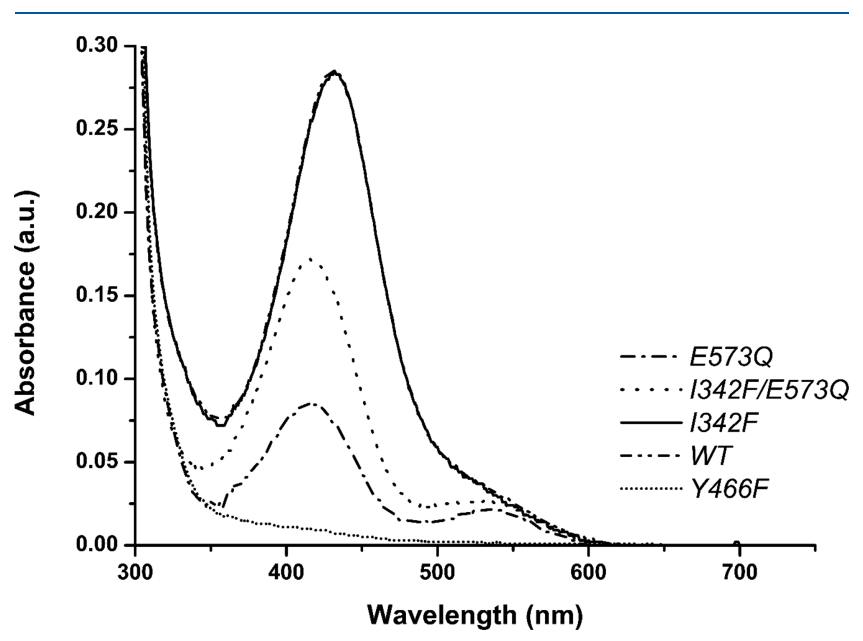

Figure 4. Effects of reacting $10 \mathrm{mg} / \mathrm{mL}$ WTECAO, I342F, I342F/ E573Q or E573Q with a 10-fold molar excess of 2-HP in $100 \mathrm{mM}$ sodium phosphate $(\mathrm{pH} 7.0)$ at $25^{\circ} \mathrm{C}$.

observed with prolonged incubation at room temperature in I342F/E573Q. ${ }^{59}$ By contrast, for WTECAO and I342F, only the hydrazone form of adduct I was detected. No spectral change was observed for Y466F as expected (Figure 4).

Table 1. Kinetic Parameters for the Reaction with $\beta$-PEA and $\mathrm{O}_{2}$, Measured in $100 \mathrm{mM}$ Sodium Phosphate (pH 7.0)

$\begin{array}{llllll} & & \text { WTECAO } & \text { I342F } & \text { E573Q/I342F } & \text { E573Q } \\ \beta \text {-PEA } & k_{\text {cat }}\left(\mathrm{s}^{-1}\right) & 14.6 \pm 0.5 & 16.5 \pm 0.6 & 0.67 \pm 0.004 & 0.15 \pm 0.0007 \\ & K_{\mathrm{M}}(\mu \mathrm{M}) & 1.3 \pm 0.2 & 1.4 \pm 0.2 & 1.4 \pm 0.03 & 1.1 \pm 0.21 \\ & k_{\text {cat }} / K_{\mathrm{M}}\left(\mu \mathrm{M}^{-1} \mathrm{~s}^{-1}\right) & 11 \pm 1.8 & 12 \pm 1.7 & 0.48 \pm 0.021 & 0.14 \pm 0.026 \\ & \text { relative activity }(\%) & 100 & 113 & 4.6 & 1 \\ \mathrm{O}_{2} & k_{\text {cat }}\left(\mathrm{s}^{-1}\right) & 43.2 \pm 1 & 59.6 \pm 5.4 & 1.67 \pm 0.09 & 0.49 \pm 0.02 \\ & K_{\mathrm{M}}(\mu \mathrm{M}) & 25.2 \pm 3.8 & 24.1 \pm 2.7 & 20.7 \pm 2.2 & 16.6 \pm 2 \\ & k_{\text {cat }} / K_{\mathrm{M}}\left(\mu \mathrm{M}^{-1} \mathrm{~s}^{-1}\right) & 1.7 \pm 0.26 & 2.8 \pm 0.37 & 0.81 \pm 0.1 & 0.3 \pm 0.04 \\ & \text { relative activity }(\%) & 100 & 138 & 3.9 & 1.1\end{array}$


A shift from the hydrazone to azo form of adduct I was observed only when WT-2HP and I342F-2HP complexes were heated (Figure 5). At $50{ }^{\circ} \mathrm{C}$, the $\lambda_{\max }$ shifts from 432 to

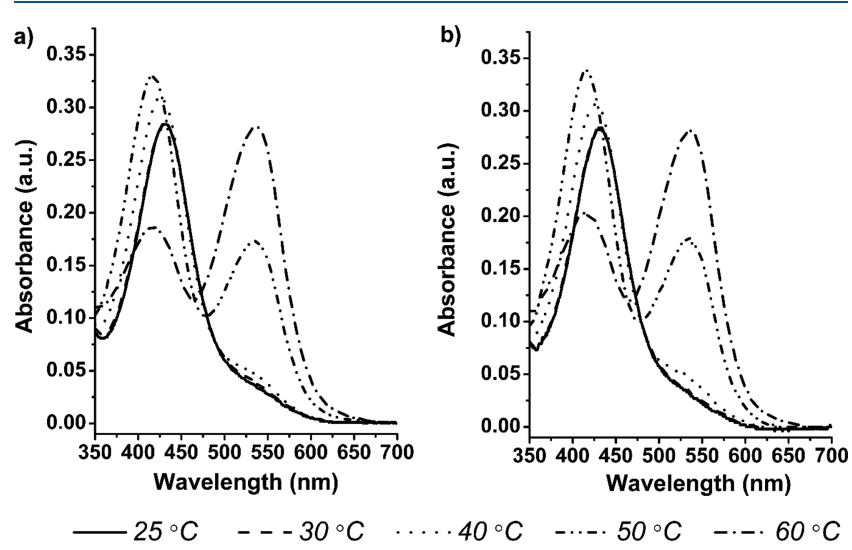

Figure 5. Effect of temperature on the hydrazone form of adduct I in (a) WTECAO and (b) I342F.

$416 \mathrm{~nm}$ with a further increase in absorbance (Figure 5). A significant increase in adduct II was also observed at $50{ }^{\circ} \mathrm{C}$ (Figure 5). The increase in absorbance associated with the conversion of hydrazone adduct I $(432 \mathrm{~nm})$ to azo adduct I $(416 \mathrm{~nm})$ in WT and I342F suggests the molar extinction coefficient for the azo form is higher than that of the hydrazone form, consistent with previous reports (Figure 5). ${ }^{59}$

The formation of adduct II has been associated with active site mutations that alter the hydrogen-bonding network within the active site, resulting in greater flexibility of the TPQ-2HP complex. An increase in temperature may also induce large movements that enable the TPQ-2HP complex to coordinate the active site $\mathrm{Cu}^{2+} .{ }^{59}$ In this case, the data provide an indication that mutations E573Q and E573Q/I342F may influence the active site to promote formation of adduct II in a proportion of the molecules at low temperatures (Figure 4), but further characterization would be required to confirm this.

Effects of the Long-Range Mutations on the Catalytic Intermediates. The levels of $\mathbf{5}$ (Scheme 1), in the absence of oxygen, were measured in the presence and absence of $\mathrm{CN}^{-}$at $25{ }^{\circ} \mathrm{C}$. Upon reaction of WT with $\beta$-PEA under anaerobic conditions, features that are characteristic of $\mathbf{5},{ }^{21,26,60}$ i.e., three peaks at 350, 438, and $467 \mathrm{~nm}$, were observed (Figure 6). The apparent level of 5 obtained using eq 1 is $34.3 \%$ as reported in ref 61 . In the absence of $\mathrm{CN}^{-}$, the levels of $5(\sim 46.7 \mu \mathrm{M})$ were similar to those detected in the presence of $\mathrm{CN}^{-}(\sim 50 \mu \mathrm{M})$, suggesting that $\mathbf{5}$ is the major intermediate in the ECAO catalytic pathway.

Removal of $\mathrm{Ca}^{2+}$ from the surface metal site resulted in a 37fold decrease in the specific activity of the protein, consistent with previous work ${ }^{13}$ (Table 2). Incubating the EDTA-treated

Table 2. Specific Activities (micromoles per minute per milligram) of WTECAO with and without EDTA Treatment or $\mathrm{Ca}^{2+}$ and $\mathrm{Cu}^{2+}$ Supplementation

$\begin{array}{ll}\text { WTECAO } & 8.6 \pm 0.4 \\ \text { EDTA-treated ECAO } & 0.23 \pm 0.04 \\ \text { EDTA-treated ECAO with } 3 \mathrm{mM} \mathrm{CaCl}_{2} & 4.4 \pm 0.32 \\ \text { EDTA-treated ECAO with } 3 \mathrm{mM} \mathrm{CaCl}_{2} \text { and } 0.05 \mu \mathrm{M} \mathrm{CuSO}_{4} & 1.7 \pm 0.4 \\ \text { WTECAO with } 3 \mathrm{mM} \mathrm{CaCl}_{2} \text { and } 0.05 \mu \mathrm{M} \mathrm{CuSO}_{4} & 4.6 \pm 0.7\end{array}$

WT enzyme with $3 \mathrm{mM} \mathrm{CaCl}_{2}$ (1000-fold excess) resulted in an increase in the specific activity to half that of the WT (Table $2)$. Analysis of metal content by Smith et al. ${ }^{13}$ showed that WTECAO contained $1.05 \pm 0.01$ coppers per subunit and that following incubation with EDTA it retained $0.95 \pm 0.05$ copper per subunit, demonstrating that the deeply buried active site copper is tightly bound and not accessible to EDTA, which suggests that a lack of recovery of enzyme activity is not due to the loss of the active site copper. ${ }^{13}$

EDTA-treated WT, EDTA-treated WT with $3 \mathrm{mM} \mathrm{CaCl}_{2}$, and WT were reacted with $\beta$-PEA under anaerobic conditions. At equal concentrations of $\mathbf{1}$ (Figure $7 \mathrm{~b}$ ), a significant difference in the levels of $\mathbf{5}$ was observed in these samples (Figure 7). The difference spectra were obtained by subtracting the initial state of the enzyme (1) (Figure 7c). On the basis of the $\varepsilon_{468}$ for $\mathrm{TPQ}_{\mathrm{SQ}}\left(4500 \mathrm{M}^{-1} \mathrm{~cm}^{-1}\right)$ reported for the A. globiformis enzyme, ${ }^{25} 1.3$ and $2.7 \mu \mathrm{M} 6$ were detected in EDTA-treated WT with $3 \mathrm{mM} \mathrm{CaCl}_{2}$ and WT, respectively. The levels of $\mathbf{5}$ formed in these samples correlate with the observed specific activities. EDTA-treated WT with 3 $\mathrm{mM} \mathrm{CaCl} \mathrm{Cl}_{2}$ displayed $50 \%$ of the WT level of $\mathbf{5}$ and exhibited $\sim 50 \%$ of WT activity (Figure 7). The amount of 5 in EDTAtreated WT was significantly smaller.

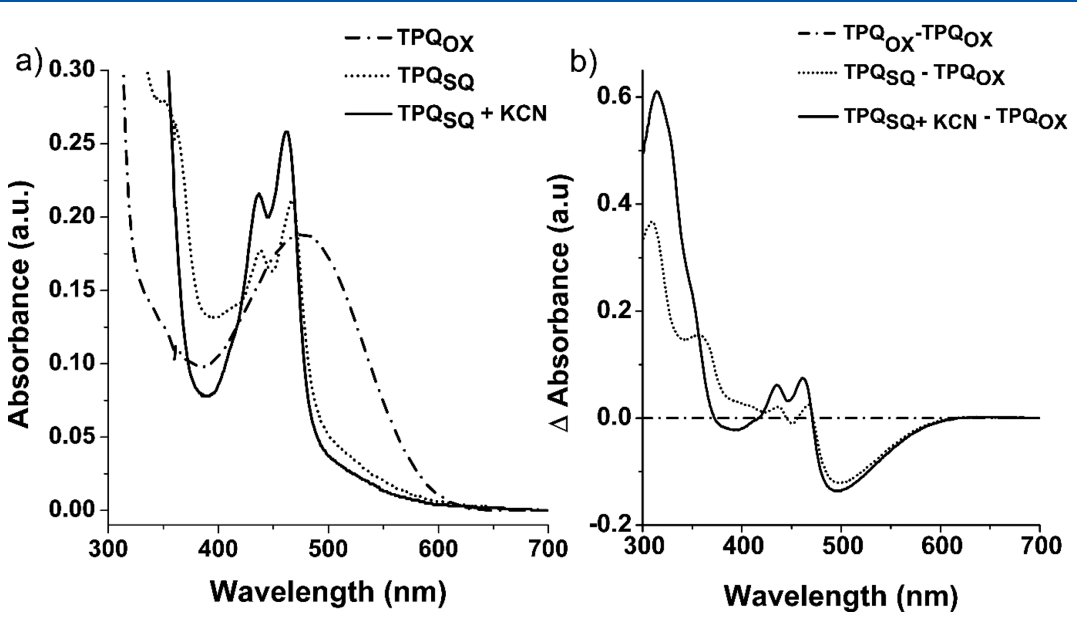

Figure 6. Anaerobic reduction of WTECAO with $\beta$-PEA at $25{ }^{\circ} \mathrm{C}$ in the absence $\left(\mathrm{TPQ}_{\mathrm{red}}\right)$ and presence of cyanide $(\mathrm{TPQ}$ red+KCN $)$ : (a) $\mathrm{UV}-\mathrm{vis}$ spectra and (b) difference spectra. 


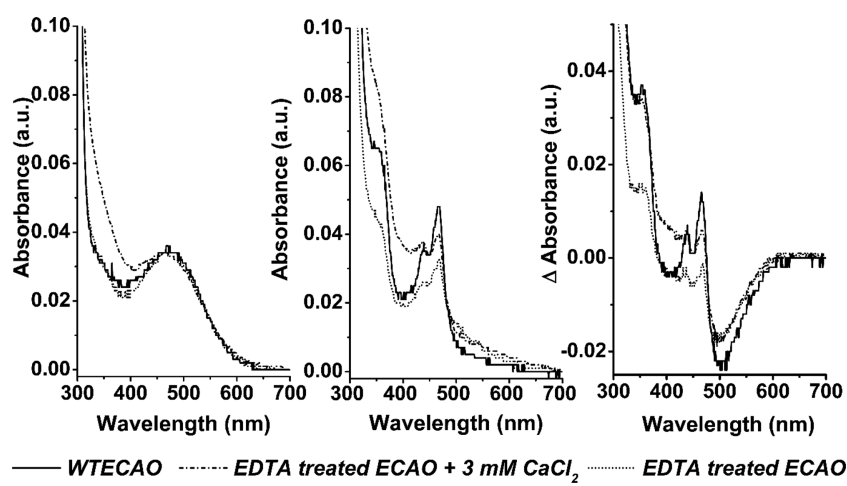

Figure 7. Effect of EDTA and $\mathrm{Ca}^{2+}$ treatment on the $\mathrm{Cu}^{+}-\mathrm{TPQ}_{S \mathrm{Q}}$ and $\mathrm{Cu}^{2+}-\mathrm{TPQ}_{\mathrm{AMO}}$ equilibrium in WTECAO at $25{ }^{\circ} \mathrm{C}$ : (a) TPQ content, (b) $\mathrm{Cu}^{+}-\mathrm{TPQ}_{\mathrm{sQ}}$ content, and (c) difference spectra of $\mathrm{Cu}^{+}-\mathrm{TPQ} \mathrm{sQ}$.

To further investigate the differences in the turnover rate and active site environments, the reductive half-reaction for each enzyme was monitored under anaerobic conditions. Before reaction, the $\mathrm{UV}-$ vis spectra of $\mathrm{WT}, \mathrm{I} 342 \mathrm{~F}$, and
E573Q/I342F displayed a $\lambda_{\max }$ at $480 \mathrm{~nm}$ confirming the presence of TPQox (1) (Figure 8). Characteristic features of 5 were observed for WT and I342F (Figure 8). The spectra for both proteins displayed peaks at 438 and $467 \mathrm{~nm}$ and a small shoulder at $357 \mathrm{~nm}$, features that have been previously assigned to $5^{21,26}$ Difference spectra for WT and I342F obtained by subtracting the initial state of TPQ from the reduced state showed the presence of both $4(310 \mathrm{~nm})$ and 5 $(310,438$, and $467 \mathrm{~nm})$ as previously observed for PSAO and AGAO. ${ }^{21,26,60}$

At TPQ concentrations similar to that of $\mathrm{WT}$, the difference spectrum of I342F/E573Q on reduction with $\beta$-PEA under $\mathrm{N}_{2}$ saturating conditions showed only the characteristic features of 4, a peak, at $310 \mathrm{~nm}$ (Figure 9). Similar treatment of E573Q also resulted in only 4 , the intermediate observed in substratereduced $\mathrm{HPAO}, \mathrm{BSAO}, \mathrm{Co}^{2+}$-AGAO, and $\mathrm{Ni}^{2+}$-AGAO (Figure 9). ${ }^{22,30,62,63}$ Although different catalytic species were observed, TPQ was successfully regenerated in all four proteins: WT, I342F, I342F/E573Q and E573Q (Figures 8 and 9).
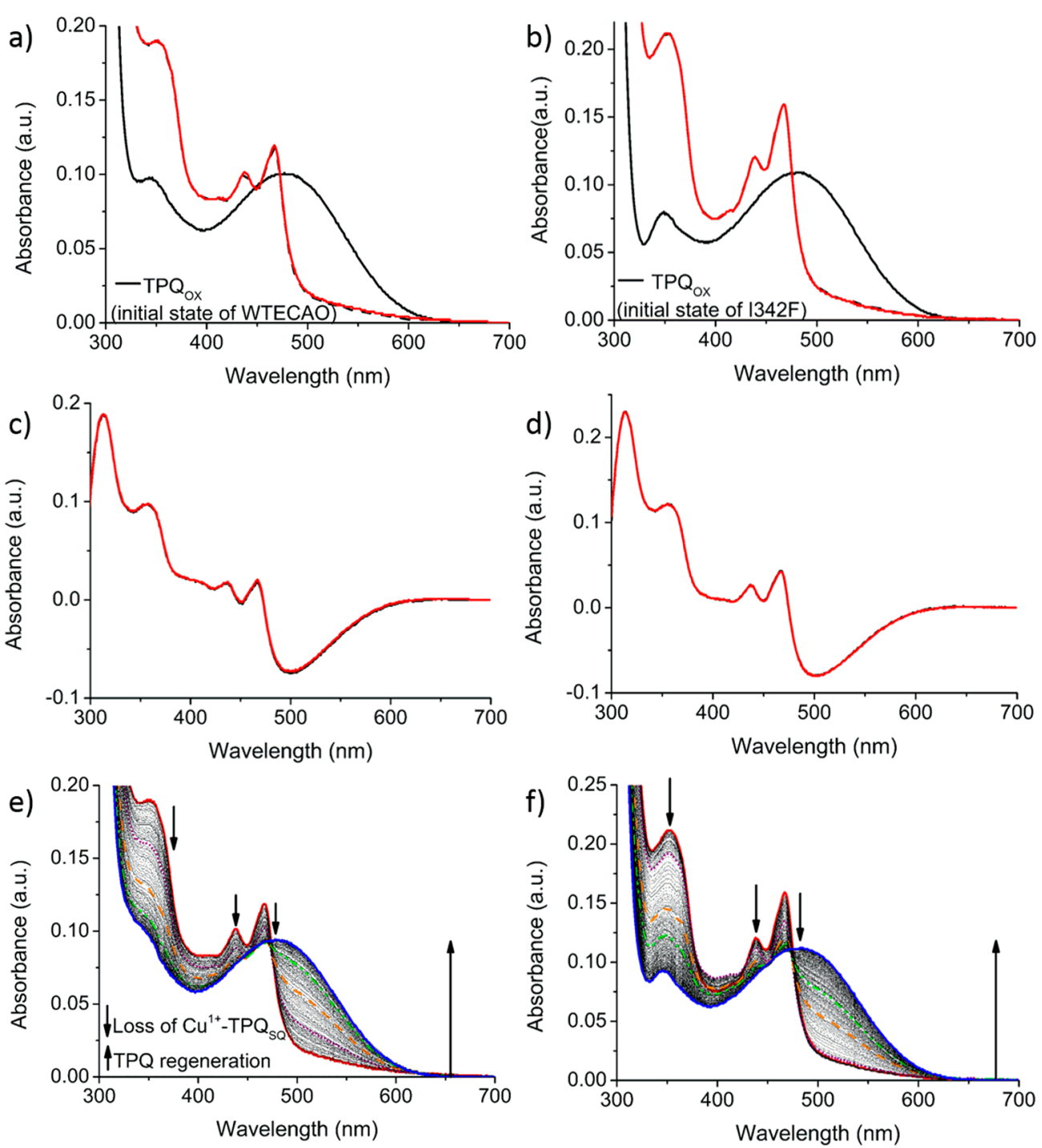

Figure 8. Spectroscopic reactivity of anaerobically substrate-reduced (a, c, and e) WTECAO and (b, d, and f) I342F at $25^{\circ} \mathrm{C}$. (a and b) Reductive half-reactions, ( $c$ and d) difference spectra for the reductive half-reactions, and (e and f) oxidative half-reactions. Spectral changes were recorded every $0.1 \mathrm{~s}$; the red spectrum was measured at $0.3 \mathrm{~s}$, the purple spectrum at $4.1 \mathrm{~s}$, the green spectrum at $6.7 \mathrm{~s}$, and the blue spectrum at $14.3 \mathrm{~s}$. 

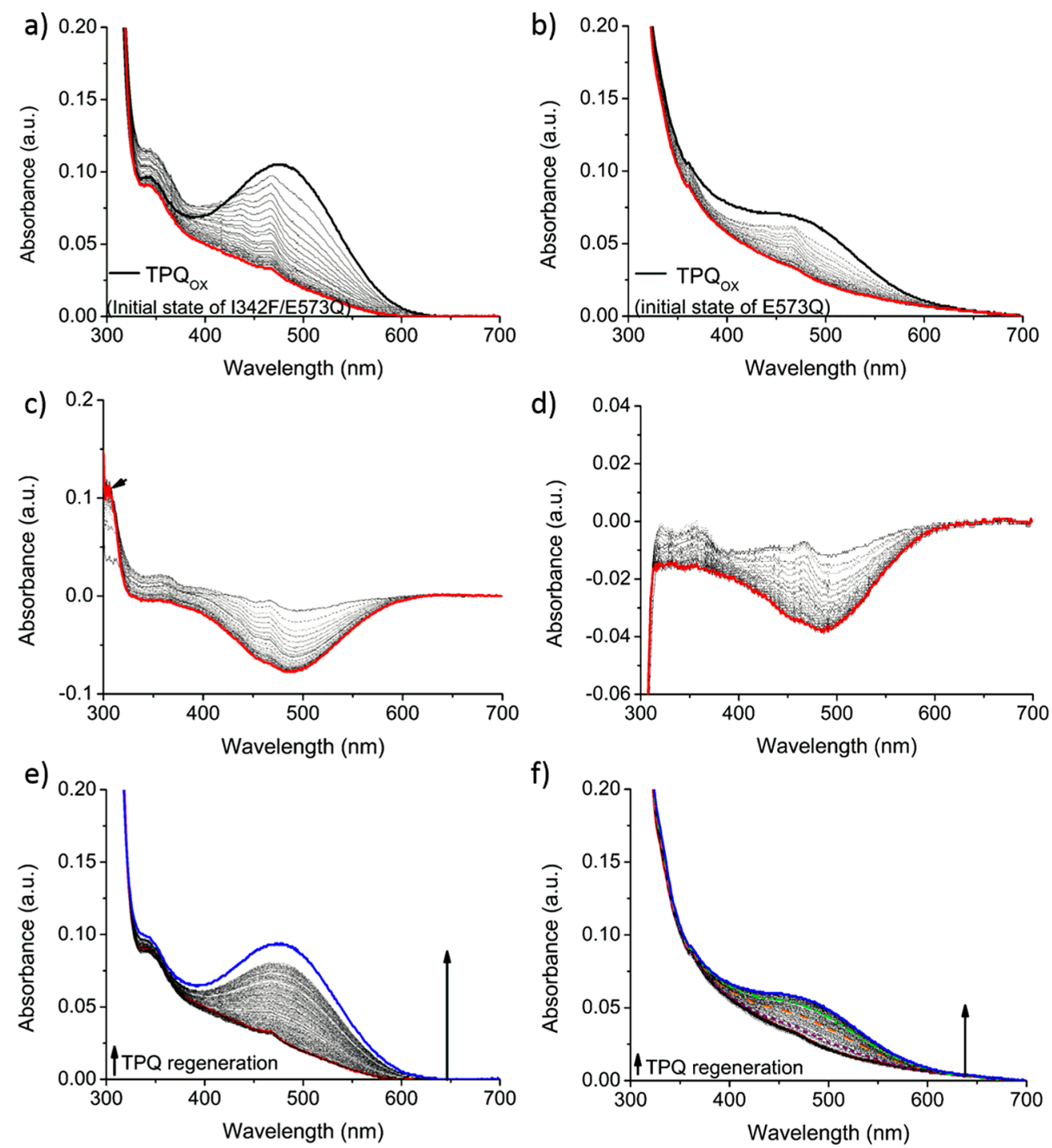

Figure 9. Spectroscopic reactivity of anaerobically substrate-reduced (a, c, and e) I342F/E573Q and (b, d, and f) E573Q at $25{ }^{\circ} \mathrm{C}$. (a and b) Reductive half-reactions, ( $c$ and d) difference spectra for the reductive half-reactions, and (e and $\mathrm{f}$ ) oxidative half-reactions. Spectral changes were recorded every $0.1 \mathrm{~s}$; the red spectrum was measured at $3.3 \mathrm{~s}$, the purple spectrum at $9.3 \mathrm{~s}$, the green spectrum at $10.7 \mathrm{~s}$, and the blue spectrum at $15.8 \mathrm{~s}$.

Crystal Structure Analysis. To understand the effects of the mutations and in particular those of $\mathrm{I} 342 \mathrm{~F}$ in the background of mutation E573Q crystal structures of E573Q/I342F [Protein Data Bank (PDB) entry 6GRR] and E573Q (PDB entry 6EZZ) were determined by X-ray crystallography and refined to 1.7 and $1.8 \AA$, respectively. The data collection and processing statistics are shown in Table S1. The mutant structures showed a high level of structural similarity to WTECAO, with the most significant differences occurring at the active site and mutation sites.

No TPQ was observed in the structure of either mutant; rather, the $2 F_{o}-F_{c}$ maps showed well-defined electron density corresponding to a tyrosine residue directly coordinated to the copper as observed in the early stages of TPQ biogenesis (Figure 10). ${ }^{11}$ There is some extra electron density at the C2 and $\mathrm{O} 4$ positions of Y466 in both structures (Figure 10a,b), and this is more evident in I342F/E573Q in the $F_{o}-F_{c}$ map (green mesh) in Figure 10b. This was expected for E573Q as the biochemical and mass spectrometry studies did not detect significant levels of TPQ. However, this was not the case with
I342F/E573Q where 60\% of the WTECAO TPQ content was observed. This may indicate substantial flexibility or preferential crystallization of the precursor form. Collecting data at room temperature may provide more information with regard to TPQ flexibility. ${ }^{64}$

In addition to the lack of the TPQ, subtle changes were observed in the active sites of both I342F/E573Q and E573Q. Comparison between these two variants and the 1DYU (offcopper) ${ }^{16}$ WTECAO active site (Figure $11 \mathrm{a}, \mathrm{b}$ ) showed that H526, D383, and M699 each displayed positional flexibility. In particular, C3 of M699 is rotated $\sim 45^{\circ}$ toward the $\mathrm{C} 3$ position of Y466 (Figure 11a,b), where oxygen is proposed to attack the aromatic ring during the first step of TPQ biogenesis to yield dopaquinone. ${ }^{11}$ Superimposing the E573Q and I342F/E573Q structures onto the 1OAC (on-copper) WTECAO ${ }^{55}$ structure showed that for both variants M699 still displays a different conformation and D383 adopts a conformation similar to that observed when TPQ is present in its "on-copper" conformation $^{55}$ (Figure 11c,d). 

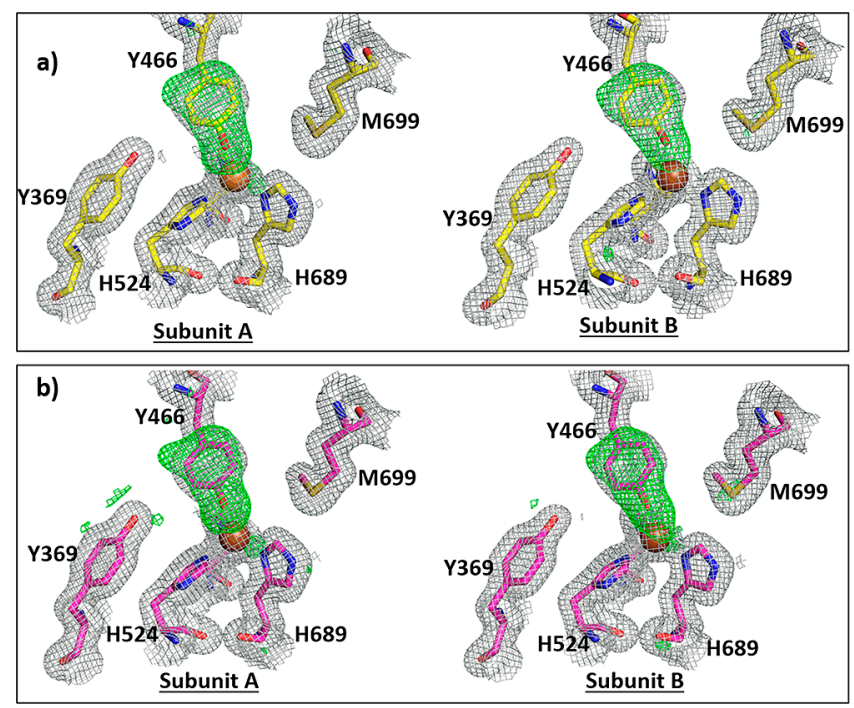

Figure 10. Electron density maps of the (a) E573Q (PDB entry 6EZZ) and (b) I342F/E573Q (PDB entry 6GRR) active sites. The $2 F_{\mathrm{o}}-F_{\mathrm{c}}$ (gray mesh) and $F_{\mathrm{o}}-F_{\mathrm{c}}$ (green mesh) maps are contoured at 1 and 3 rmsd, respectively.

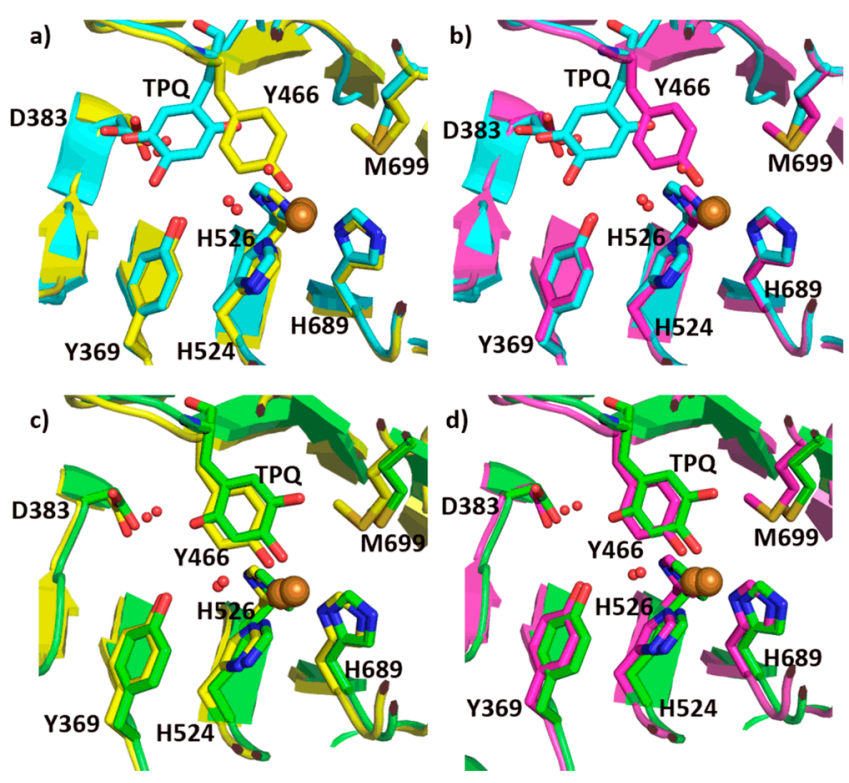

Figure 11. Superposition of the E573Q (yellow) and I342F/E573Q (magenta) active sites onto ( $a$ and $b$ ) WTECAO, where TPQ is in the "off-copper" conformation (PDB entry 1DYU) (cyan), and (c and d) WTECAO, where TPQ is in the "on-copper" conformation (PDB entry $1 \mathrm{OAC})$ (green).

Exterior to the active site, while the 1DYU WTECAO structure shows differences in the surface metal (calcium ion) site for the two crystallographically independent subunits of $\mathrm{ECAO}$, when residue 573 is mutated from glutamate to glutamine the ECAO loses its ability to bind a metal ion at this site (Figure 12). In subunit A of both E573Q and I342F/ $\mathrm{E} 573 \mathrm{Q}$, the calcium ion is replaced by a water molecule; however, in subunit B, no water molecule is observed (Figure $12 \mathrm{a}, \mathrm{b})$. The lack of a surface metal site in E573Q and I342F/ E573Q results in a significant increase in flexibility as indicated by the $B$ factor values (Figure $12 \mathrm{~d}$ ) and poorly defined sidechain electron density in loops 569-574 and 667-673. In contrast to E573Q mutation I342F has no obvious effects on
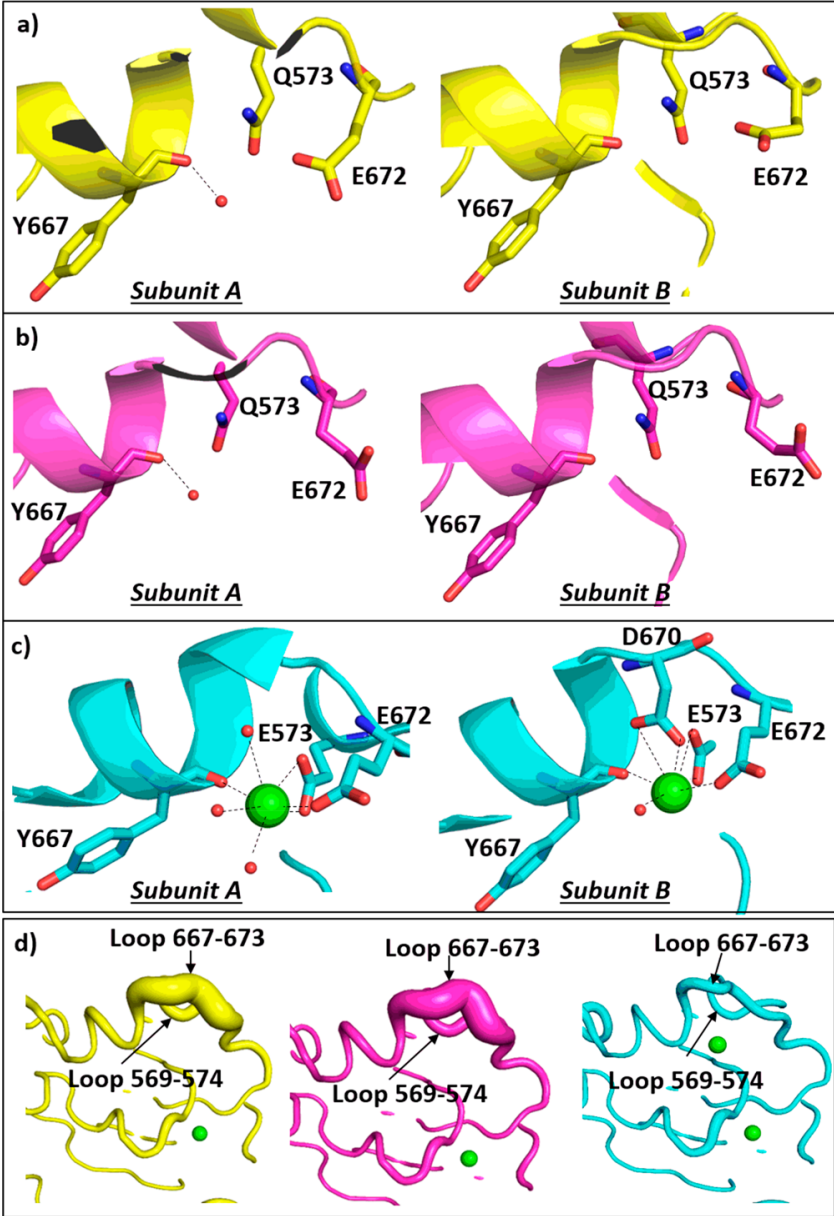

Figure 12. Structures of peripheral surface metal sites of (a) E573Q (yellow), (b) I342F/E573Q (magenta), and (c) WTECAO (PDB entry 1DYU) (cyan). (d) Structures of subunit A with $B$ factors for individual atoms represented by a ribbon structure in which the ribbon thickness indicates the magnitude of the $B$ factor; thin indicates low $B$ factors, and thick indicates high $B$ factors. Bound calcium ions are represented as green spheres, whereas in panel d, the surface and buried calcium sites are represented by the top and bottom green spheres, respectively.

the overall structure of the enzyme. F342 has fewer rotational degrees of freedom than isoleucine does and fits perfectly in the hydrophobic channel partially stacking with W472 (Figure 13).

\section{DISCUSSION}

The E573Q mutation, some $32 \AA$ from the active site, has a major long-range conformational effect on the formation of TPQ and catalytic turnover. Residue 573 is located near the opening of the hydrophobic channel identified as the putative $\mathrm{O}_{2}$ delivery pathway. Although low levels of TPQ were detected for this variant (16\% WT TPQ), attempts to drive TPQ biogenesis under $\mathrm{O}_{2}$ saturating conditions failed, demonstrating the inability of the mutant to activate $\mathrm{O}_{2}$ for TPQ formation. A comparison of the structure of WTECAO with E573Q shows only minor changes at the active site and surface mutation site. The lack of efficient TPQ processing in E573Q may be due to (a) a change in the geometry and/or bond lengths in the copper primary coordination sphere, (b) an inability to form the ligand to metal charge transfer (LMCT) complex required for $\mathrm{O}_{2}$ activation, and/or (c) the 

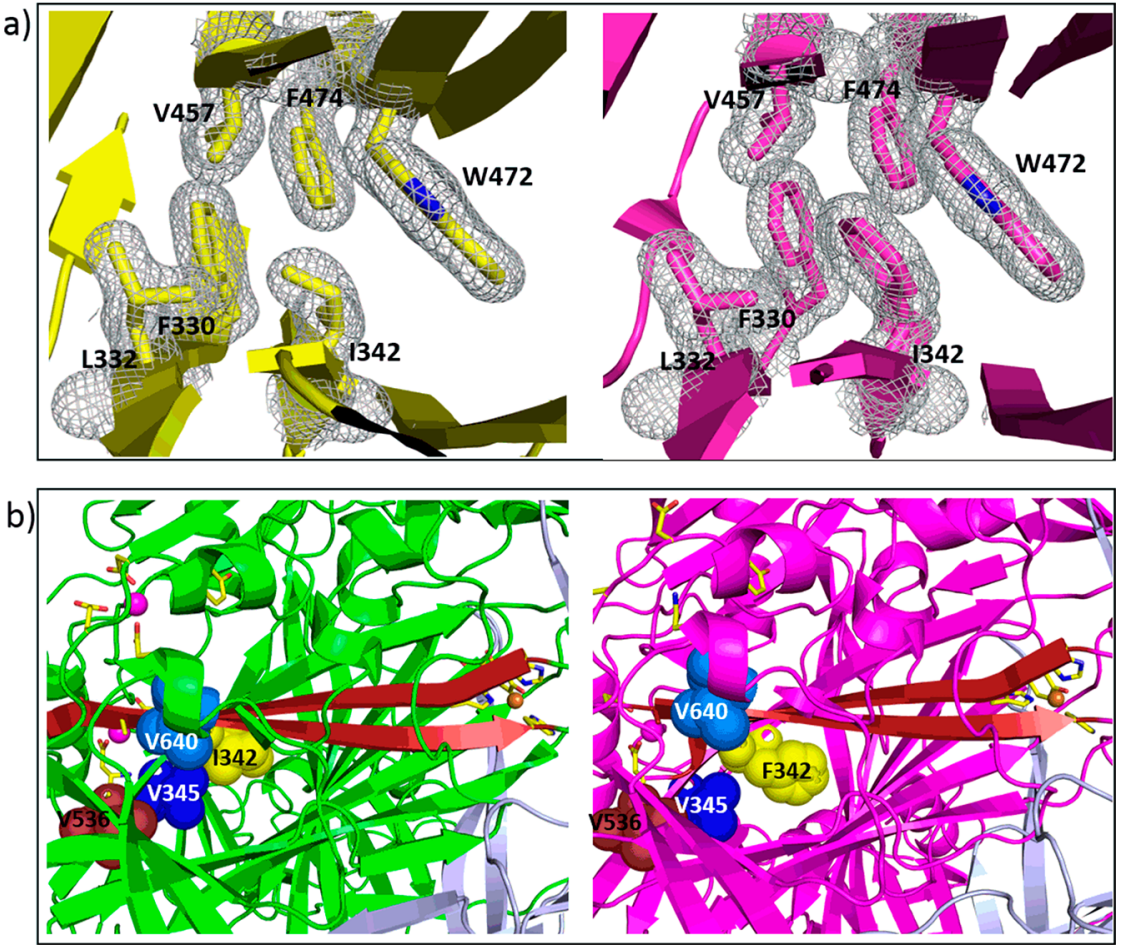

Figure 13. Structure of the putative oxygen entry channel. (a) The $2 F_{\mathrm{o}}-F_{\mathrm{c}}$ map is contoured at $1 \mathrm{rmsd}$ showing the electron density of residues in the hydrophobic channel as a gray mesh: E573Q (yellow) and I342F/E573Q (magenta). (b) View down the channel highlighting residues mutated in ref 41 and in this study: WTECAO (green) and I342F/E573Q (magenta).

inability of $\mathrm{O}_{2}$ to enter the active site or adopt a productive position due to alterations in ECAO dynamics associated with the preferred $\mathrm{O}_{2}$ entry channel.

The first two suggestions can be dismissed as the E573Q copper tetrahedral geometry and the distances between copper and tyrosine are identical to those reported for other $\mathrm{CuAO}$ precursor states, ${ }^{65,66}$ and the distance between copper and histidine is similar to that of WTECAO (Figure S6). ${ }^{16}$ However, fine-tuning an optimized structure of the copper coordination sphere(s) is known to be important for both cofactor biogenesis and catalysis. ${ }^{13,66,67}$ Potentially subtle changes, beyond the detection limit of crystallography, in the positioning of copper, the three histidines, and key side chains ${ }^{60}$ may have conceivably stalled biogenesis. Currently, during TPQ biogenesis in ECAO, there are no reported data to suggest the formation of an LMCT intermediate, a species successfully observed and characterized in HPAO. ${ }^{58}$ Furthermore, attempts to detect a $350 \mathrm{~nm} \mathrm{Cu(II)-tyrosinate} \mathrm{complex}$ spectrophotometrically, even in the presence of a saturating level of $\mathrm{O}_{2}$, were unsuccessful, and as no such complex has been observed in AGAO, ${ }^{11}$ it may not occur in any bacterial CuAO.

The proposed rate-limiting step in biogenesis is the formation of a peroxy intermediate that occurs as a result of direct electron transfer from the metal-coordinating tyrosinate complex to the bound $\mathrm{O}_{2}{ }^{68} \mathrm{It}$ is possible that changes in active site flexibility or dynamic motions, demonstrated by the preferred formation of a copper-coordinated TPQ-2HP species (adduct II) in E573Q inhibit the accessibility of $\mathrm{O}_{2}$ proximal to precursor Y466 where some effect of a steric/ electronic clash, on $\mathrm{O}_{2}$ activation, could disfavor formation of a peroxy-Cu(II)-bound intermediate. TPQ biogenesis has been shown to be a dynamic process requiring rotation of the precursor tyrosine and surrounding side chains during the reaction. ${ }^{11}$ In the crystal structures of both E573Q and I342F/ E573Q the hydrophobic channel remains open; however, because of the bulky nature of phenyalanine at position 342 the channel is narrower in $\mathrm{I} 342 \mathrm{~F} / \mathrm{E} 573 \mathrm{Q}$ (Figure 13b) than in E573Q although $\mathrm{O}_{2}$ delivery is apparently more efficient in the former based on TPQ formation. Therefore, protein dynamics are likely to play a key role in the improved delivery of $\mathrm{O}_{2}$ to the active site for TPQ biogenesis.

To probe oxygen entry and/or delivery, multiple residues were mutated in the $\beta$-sandwich funnel (hydrophobic channel). ${ }^{41}$ In the E573Q background, the addition of the I342F mutation led to a partial rescue of TPQ biogenesis, reaching $60 \%$ of that of $\mathrm{WT}$. Associating the reactivation of TPQ biogenesis in the double mutant with an improvement in the delivery of $\mathrm{O}_{2}$ to the active site is tempting as $\mathrm{I} 342$ corresponds to a "hinge" region connecting two critical regions of the putative hydrophobic oxygen entry channel. However, there is no direct link between residues E573 and I342 and the active site residues required for TPQ biogenesis. Possible reasons for the recovery of TPQ biogenesis in I342F/E573Q are that the $\mathrm{I} 342 \mathrm{~F}$ mutation has physically levered open the hydrophobic channel by increasing the steric bulk at the hinge region to promote access of $\mathrm{O}_{2}$ to the active site or it counteracts the dynamic effects imposed by the E573Q mutation allowing activation of $\mathrm{O}_{2}$ by the LMCT complex. Exposing E573Q that had been held under $\mathrm{N}_{2}$ saturating conditions to air led to the reoxidation of the small amounts of TPQ present, indicating that access of $\mathrm{O}_{2}$ to the active site is not entirely blocked (Figure 10d).

While xenon complex crystal structures and in silico experiments identified a major putative $\mathrm{O}_{2}$ entry pathway, mutagenesis experiments designed to block individual path- 
Scheme 2. Proposed Mechanism for TPQ Biogenesis in Copper Amine Oxidases ${ }^{73}$

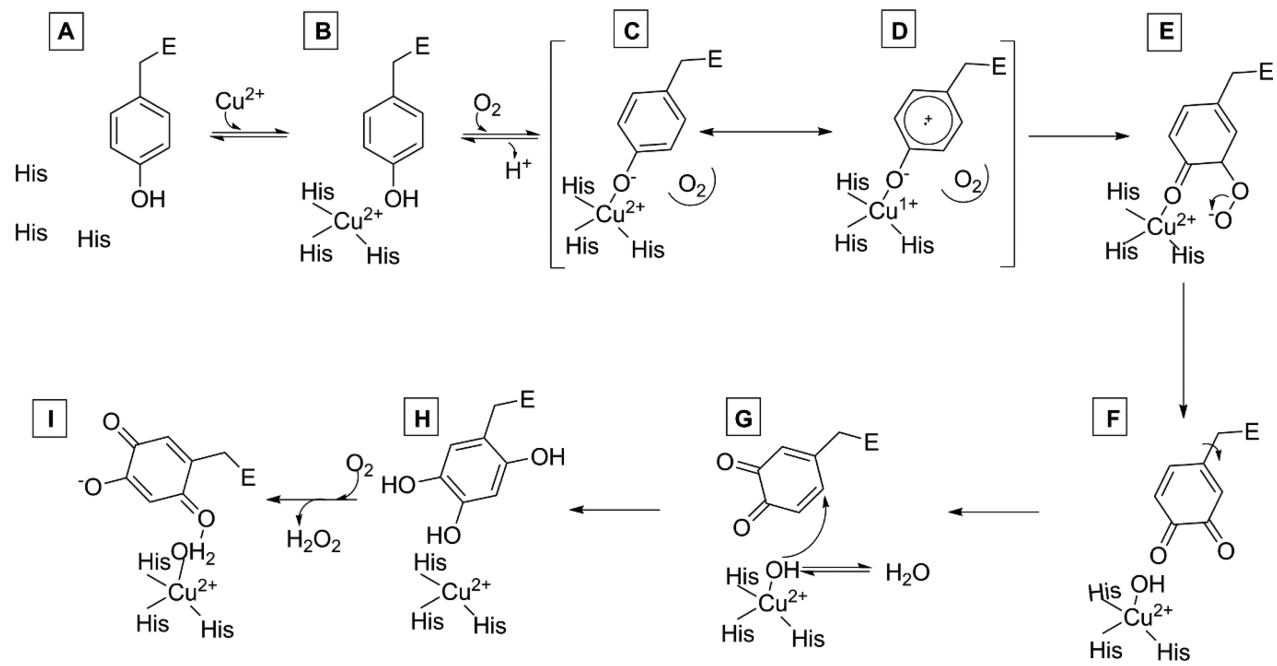

ways have had little effect on the overall $k_{\text {cat }} / K_{\mathrm{M}}$, implying that $\mathrm{O}_{2}$ uses multiple dynamic routes to reach the active site. ${ }^{69}$ One possibility is that two different $\mathrm{O}_{2}$ pathways are employed for TPQ biogenesis and the catalysis of $\mathrm{O}_{2}$ reduction.

There is no structural evidence of the effects afforded by the I342F mutation; however, inhibition studies using $2 \mathrm{HP}$ highlighted differences in the active sites of I342F/E573Q (adduct II) and WT (adduct I), suggesting increased active site flexibility in the double mutant (Figure 4). Adduct II is formed when the TPQ-2HP complex rearranges to coordinate the active site $\mathrm{Cu}^{2+}$, suggesting increased flexibility in the active site. ${ }^{59}$ The formation of adduct II has previously been observed with active site mutations $\mathrm{Y} 381 \mathrm{~F}$ and $\mathrm{Y} 369 \mathrm{~F} .{ }^{59,70}$ This implies that TPQ in I342F/E573Q preferentially adopts an "oncopper" conformation unlike that in WTECAO and I342F.

Although TPQ biogenesis is reactivated in E573Q/I342F, introducing the $\mathrm{I} 342 \mathrm{~F}$ mutation does not lead to a corresponding enhancement of the catalytic activity of E573Q. To understand the effect of E573Q on catalysis, the catalytic reaction was followed under anaerobic conditions. Reducing WTECAO, I342F, I342F/E573Q, and E573Q with $\beta$-PEA under anaerobic conditions revealed an interesting and distinct difference in catalytic intermediates formed over the course of the reaction.

In WTECAO and I342F, the characteristic features of 5 were observed (Figure 8 ) and the difference spectra showed both $4(310 \mathrm{~nm})$ and $5\left(\lambda_{\max }, 357,438\right.$, and $\left.468 \mathrm{~nm}\right)$ as observed for LSAO, PSAO, AGAO, and APAO, which are all $\mathrm{CuAOs}$ that use the inner sphere electron transfer mechanism to activate $\mathrm{O}_{2} \cdot{ }^{21,23,25,26,71,72}$ In such CuAOs, the intermediates exist in an equilibrium that favors $\mathbf{5}$ and exhibit fast turnover rates as the electron transfer rate between $\mathrm{Cu}^{+}$and $\mathrm{O}_{2}$ is greater than or equal to the overall rate of turnover and thus is not the rate-limiting step. ${ }^{26,31}$ The ability to form $34 \%$ of the $\mathrm{Cu}^{+}-\mathrm{TPQ}_{\mathrm{SQ}}(5)$, as previously reported, suggests that ECAO uses the inner sphere electron transfer mechanism as reported for AGAO, another bacterial $\mathrm{CuAO}{ }^{25,31}$

For E573Q and I342F/E573Q the difference spectra showed only the characteristic feature for $\mathbf{5}$ as observed with BSAO and HPAO, CuAOs that use the outer sphere electron transfer mechanism. ${ }^{29,30,63}$ The ability of a second sphere residue to influence the equilibrium between 4 and 5 has been shown with HPAO. ${ }^{22}$ Detecting only 4 in E573Q and I342F/
E573Q suggests a shift in the equilibrium in favor of $\mathbf{5}$. The $\sim 100$-fold decrease in activity of E573Q can be explained by a change from the inner to outer sphere electron transfer mechanism. If this is the case, the data presented here represent the first report in $\mathrm{CuAOs}$ of a residue distant from the active site affecting the properties of the redox active metalloenzyme.

In support of this, removal of $\mathrm{Ca}^{2+}$ by EDTA chelation reduced activity significantly as well as the levels of intermediate 5. Addition of $\mathrm{Ca}^{2+}$ to the same sample partially restored activity and increased $\mathbf{5}$ levels, confirming that the peripheral metal sites play a role in regulating the equilibrium that exists between 4 and 5. These data also support the hypothesis that ECAO uses the inner sphere electron transfer mechanism in the oxidative half-reaction and demonstrates an allosteric role for $\mathrm{Ca}^{2+}$ sites. Mammalian CuAOs, BSAO, VAP1 , and hDAO have been shown to have a surface metal binding site similar to that of ECAO. It is possible that in mammalian systems, control of $\mathrm{Ca}^{2+}$ availability may represent a method for regulating the $\mathrm{CuAO}$ activity and thereby controlling the production of $\mathrm{H}_{2} \mathrm{O}_{2}$ that can be important in cell signaling but that, together with product aldehydes, can in excess be detrimental to cells.

E573Q affects the enzyme's ability to form 5 interfering with the redox potential of the $\mathrm{Cu}^{2+} / \mathrm{Cu}^{+}$couple such that reduction to $\mathrm{Cu}^{+}$is disfavored. This would suggest that the E573Q mutation results in a substantially weakened ability to form the $\mathrm{Cu}^{+}$-tyrosyl radical intermediate thus stalling TPQ biogenesis at the $\mathrm{O}_{2}$ activation stage ( $D$ in Scheme 2). The E573Q crystal structure supports this hypothesis as Y466 interacts with the copper ion at a bond distance of $2.03 \AA$, resembling the structures observed in the early stages of TPQ biogenesis and suggesting that biogenesis is stalled after the deprotonation of Y466. The improvement in TPQ biogenesis associated with the $\mathrm{I} 342 \mathrm{~F}$ mutation may result from changes in the dynamic behavior of the enzyme. These changes may be a result of improved structural stability associated with the stacking interaction between W472 and F342 in I342F/E573Q. It is still reasonable to associate this improvement in TPQ biogenesis with improved delivery of $\mathrm{O}_{2}$ to the active site. 


\section{CONCLUSION}

Through a combination of biochemical and site-directed mutagenesis studies, we have demonstrated a likely regulatory role for the surface metal site in ECAO. Removing the surface site $\mathrm{Ca}^{2+}$ by chelation or mutagenesis (E573Q) affects TPQ biogenesis and catalytic efficiency in amine oxidation at the active site, some $32 \AA$ away. This interferes with the $\mathrm{Cu}^{2+} / \mathrm{Cu}^{+}$ couple and supports the proposal of an inner sphere electron transfer mechanism in this enzyme. EPR spectroscopy studies will provide more insight into the effects of the E573Q mutation on the redox state of copper. The lack of obvious structural differences in the crystal structures of the mutants and WTECAO suggests a role for protein dynamics in transmitting the effects of mutations that are $32 \AA$ (E573Q) and $22 \AA$ (I342F) from the active site. Reactivation of TPQ biogenesis in I342F/E573Q could be associated with improved delivery of $\mathrm{O}_{2}$ to the active site. Further studies to understand the role of the surface site in ECAO dynamics and delivery of $\mathrm{O}_{2}$ to the active site remain an important goal.

\section{ASSOCIATED CONTENT}

\section{S Supporting Information}

The Supporting Information is available free of charge on the ACS Publications website at DOI: 10.1021/acs.biochem.8b00633.

Gel images concerning buried site mutants (Figures S1 and S2), relative specific activity data for mutant proteins (Figures S3-S5), comparison of the copper sites of WT, I342F/E573Q and E573Q proteins (Figure S6), and crystallographic data (Table S1) (PDF)

\section{AUTHOR INFORMATION}

\section{Corresponding Author}

*E-mail: m.j.mcpherson@leeds.ac.uk.

\section{ORCID $\odot$}

Michael J. McPherson: 0000-0002-0719-6427

\section{Funding}

This work was supported by the Biotechnology and Biological Sciences Research Council (Grant BB/C00468X/1). T.G.G. was supported by a BBSRC studentship, P.P. by Wellcome Trust Studentship Award 072570/Z/03/Z, and K.M.T. by an EPSRC studentship and The Leverhulme Trust.

\section{Notes}

The authors declare no competing financial interest.

\section{DEDICATION}

This work is dedicated to Peter F. Knowles, who sadly and unexpectedly died in 2015 having made major contributions to the copper amine oxidase field since the 1960s.

\section{REFERENCES}

(1) Angelini, R., Cona, A., Federico, R., Fincato, P., Tavladoraki, P., and Tisi, A. (2010) Plant amine oxidases "on the move": An update. Plant Physiol. Biochem. 48, 560-564.

(2) Cona, A., Rea, G., Angelini, R., Federico, R., and Tavladoraki, P. (2006) Functions of amine oxidases in plant development and defence. Trends Plant Sci. 11, 80-88.

(3) Dunkel, P., Gelain, A., Barlocco, D., Haider, N., Gyires, K., Sperlagh, B., Magyar, K., Maccioni, E., Fadda, A., and Matyus, P. (2008) Semicarbazide-sensitive amine oxidase/vascular adhesion protein 1: Recent developments concerning substrates and inhibitors of a promising therapeutic target. Curr. Med. Chem. 15, 1827-1839.
(4) Maintz, L., Schwarzer, V., Bieber, T., van der Ven, K., and Novak, N. (2008) Effects of histamine and diamine oxidase activities on pregnancy: a critical review. Hum. Reprod. Update 14, 485-495.

(5) McDonald, A., Tipton, K., O’Sullivan, J., Olivieri, A., Davey, G., Coonan, A. M., and Fu, W. (2007) Modelling the roles of MAO and SSAO in glucose transport. J. Neural Trans. 114, 783-786.

(6) McGrath, A. P., Hilmer, K. M., Collyer, C. A., Shepard, E. M., Elmore, B. O., Brown, D. E., Dooley, D. M., and Guss, J. M. (2009) Structure and inhibition of human diamine oxidase. Biochemistry 48, 9810-9822.

(7) Schwelberger, H. G. (2007) The origin of mammalian plasma amine oxidases. J. Neural Trans. 114, 757-762.

(8) Toninello, A., Pietrangeli, P., De Marchi, U., Salvi, M., and Mondovi, B. (2006) Amine oxidases in apoptosis and cancer. Biochim. Biophys. Acta, Rev. Cancer 1765, 1-13.

(9) Wimalasekera, R., Villar, C., Begum, T., and Scherer, G. F. E. (2011) Copper amine oxidase1 (CuAO1) of Arabidopsis thaliana contributes to abscisic acid- and polyamine-induced nitric oxide biosynthesis and abscisic acid signal transduction. Mol. Plant 4, 663678.

(10) Cai, D., and Klinman, J. P. (1994) Evidence of a self-catalytic mechanism of 2,4,5-trihydroxyphenylalanine quinone biogenesis in yeast copper amine oxidase. J. Biol. Chem. 269, 32039-32042.

(11) Kim, M., Okajima, T., Kishishita, S., Yoshimura, M., Kawamori, A., Tanizawa, K., and Yamaguchi, H. (2002) X-ray snapshots of quinone cofactor biogenesis in bacterial copper amine oxidase. Nat. Struct. Biol. 9, 591-596.

(12) Matsuzaki, R., Fukui, T., Sato, H., Ozaki, Y., and Tanizawa, K. (1994) Generation of the topa quinone cofactor in bacterial monoamine oxidase by cupric ion-dependent autooxidation of a specific tyrosyl residue. FEBS Lett. 351, 360-364.

(13) Smith, M. A., Pirrat, P., Pearson, A. R., Kurtis, C. R. P., Trinh, C. H., Gaule, T. G., Knowles, P. F., Phillips, S. E. V., and McPherson, M. J. (2010) Exploring the roles of the metal ions in Escherichia coli copper amine oxidase. Biochemistry 49, 1268-1280.

(14) Brazeau, B. J., Johnson, B. J., and Wilmot, C. M. (2004) Copper-containing amine oxidases. Biogenesis and catalysis; a structural perspective. Arch. Biochem. Biophys. 428, 22-31.

(15) Mure, M., Mills, S. A., and Klinman, J. P. (2002) Catalytic mechanism of the topa quinone containing copper amine oxidases. Biochemistry 41, 9269-9278.

(16) Murray, J. M., Saysell, C. G., Wilmot, C. M., Tambyrajah, W. S., Jaeger, J., Knowles, P. F., Phillips, S. E., and McPherson, M. J. (1999) The active site base controls cofactor reactivity in Escherichia coli amine oxidase: $\mathrm{x}$-ray crystallographic studies with mutational variants. Biochemistry 38, 8217-8227.

(17) Wilmot, C. M., Murray, J. M., Alton, G., Parsons, M. R., Convery, M. A., Blakeley, V., Corner, A. S., Palcic, M. M., Knowles, P. F., McPherson, M. J., and Phillips, S. E. (1997) Catalytic mechanism of the quinoenzyme amine oxidase from Escherichia coli: exploring the reductive half-reaction. Biochemistry 36, 1608-1620.

(18) Wilmot, C. M., Saysell, C. G., Blessington, A., Conn, D. A., Kurtis, C. R., McPherson, M. J., Knowles, P. F., and Phillips, S. E. (2004) Medical implications from the crystal structure of a coppercontaining amine oxidase complexed with the antidepressant drug tranylcypromine. FEBS Lett. 576, 301-305.

(19) Roth, J. P. (2007) Advances in studying bioinorganic reaction mechanisms: isotopic probes of activated oxygen intermediates in metalloenzymes. Curr. Opin. Chem. Biol. 11, 142-150.

(20) Dooley, D. M., McGuirl, M. A., Brown, D. E., Turowski, P. N., McIntire, W. S., and Knowles, P. F. (1991) A Cu(I)-semiquinone state in substrate-reduced amine oxidases. Nature 349, 262-264.

(21) Medda, R., Padiglia, A., Bellelli, A., Pedersen, J. Z., Finazzi Agrò, A. F., and Floris, G. (1999) Cu-I-semiquinone radical species in plant copper-amine oxidases. FEBS Lett. 453, 1-5.

(22) Welford, R. W. D., Lam, A., Mirica, L. M., and Klinman, J. P. (2007) Partial conversion of Hansenula polymorpha amine oxidase into a "Plant" amine oxidase: Implications for copper chemistry and mechanism. Biochemistry 46, 10817-10827. 
(23) Dooley, D. M., and Brown, D. E. (1996) Intramolecular electron transfer in the oxidation of amines by methylamine oxidase from Arthrobacter P1. JBIC, J. Biol. Inorg. Chem. 1, 205-209.

(24) Juda, G. A., Shepard, E. M., Elmore, B. O., and Dooley, D. M. (2006) A comparative study of the binding and inhibition of four copper-containing amine oxidases by azide: Implications for the role of copper during the oxidative half-reaction. Biochemistry 45, 87888800 .

(25) Shepard, E. M., Okonski, K. M., and Dooley, D. M. (2008) Kinetics and spectroscopic evidence that the $\mathrm{Cu}(\mathrm{I})$-semiquinone intermediate reduces molecular oxygen in the oxidative half-reaction of Arthrobacter globiformis amine oxidase. Biochemistry 47, 1390713920.

(26) Turowski, P. N., McGuirl, M. A., and Dooley, D. M. (1993) Intramolecular electron transfer rate between active-site copper and topa quinone in pea seedling amine oxidase. J. Biol. Chem. 268, 17680-17682.

(27) Cramer, C. J., and Tolman, W. B. (2007) Mononuclear Cu-O2 Complexes: Geometries, spectroscopic properties, electronic structures, and reactivity. Acc. Chem. Res. 40, 601-608.

(28) Whittaker, J. W. (1999) Oxygen reactions of the copper oxidases. Essays Biochem. 34, 155-172.

(29) Mills, S. A., and Klinman, J. P. (2000) Evidence against reduction of $\mathrm{Cu} 2+$ to $\mathrm{Cu}+$ during dioxygen activation in a copper amine oxidase from yeast. J. Am. Chem. Soc. 122, 9897-9904.

(30) Su, Q., and Klinman, J. P. (1998) Probing the mechanism of proton coupled electron transfer to dioxygen: the oxidative halfreaction of bovine serum amine oxidase. Biochemistry 37, 1251312525 .

(31) Shepard, E. M., and Dooley, D. M. (2006) Intramolecular electron transfer rate between active-site copper and TPQ in Arthrobacter globiformis amine oxidase. JBIC, J. Biol. Inorg. Chem. 11, 1039-1048.

(32) Johnson, B. J., Cohen, J., Welford, R. W., Pearson, A. R., Schulten, K., Klinman, J. P., and Wilmot, C. M. (2007) Exploring molecular oxygen pathways in Hansenula polymorpha coppercontaining amine oxidase. J. Biol. Chem. 282, 17767-17776.

(33) Luna, V. M., Chen, Y., Fee, J. A., and Stout, C. D. (2008) Crystallographic studies of $\mathrm{Xe}$ and $\mathrm{Kr}$ binding within the large internal cavity of cytochrome ba(3) from Thermus thermophilus: Structural analysis and role of oxygen transport channels in the heme- $\mathrm{Cu}$ oxidases. Biochemistry 47, 4657-4665.

(34) Saam, J., Ivanov, I., Walther, M., Holzhutter, H. G., and Kuhn, H. (2007) Molecular dioxygen enters the active site of 12/15lipoxygenase via dynamic oxygen access channels. Proc. Natl. Acad. Sci. U. S. A. 104, 13319-13324.

(35) Saam, J., Rosini, E., Molla, G., Schulten, K., Pollegioni, L., and Ghisla, S. (2010) O-2 Reactivity of Flavoproteins dynamic access of dioxygen to the active site and role of a $\mathrm{H}^{+}$relay system in d-amino acid oxidase. J. Biol. Chem. 285, 24439-24446.

(36) Song, W. J., Gucinski, G., Sazinsky, M. H., and Lippard, S. J. (2011) Tracking a defined route for O-2 migration in a dioxygenactivating di-iron enzyme. Proc. Natl. Acad. Sci. U. S. A. 108, 1479514800 .

(37) Tomita, A., Sato, T., Ichiyanagi, K., Nozawa, S., Ichikawa, H., Chollet, M., Kawai, F., Park, S.-Y., Tsuduki, T., Yamato, T., Koshihara, S.-y., and Adachi, S.-i. (2009) Visualizing breathing motion of internal cavities in concert with ligand migration in myoglobin. Proc. Natl. Acad. Sci. U. S. A. 106, 2612-2616.

(38) Cohen, J., Arkhipov, A., Braun, R., and Schulten, K. (2006) Imaging the migration pathways for $\mathrm{O}-2, \mathrm{CO}, \mathrm{NO}$, and $\mathrm{Xe}$ inside myoglobin. Biophys. J. 91, 1844-1857.

(39) Duff, A. P., Trambaiolo, D. M., Cohen, A. E., Ellis, P. J., Juda, G. A., Shepard, E. M., Langley, D. B., Dooley, D. M., Freeman, H. C., and Guss, J. M. (2004) Using xenon as a probe for dioxygen-binding sites in copper amine oxidases. J. Mol. Biol. 344, 599-607.

(40) Pirrat, P., Smith, M. A., Pearson, A. R., McPherson, M. J., and Phillips, S. E. V. (2008) Structure of a xenon derivative of Escherichia coli copper amine oxidase: confirmation of the proposed oxygen-entry pathway. Acta Crystallogr., Sect. F: Struct. Biol. Cryst. Commun. 64, 1105-1109.

(41) Smith, M. A., Knowles, P. F., McPherson, M. J., and Pearson, A. R. (2011) Dissecting the mechanism of oxygen trafficking in a metalloenzyme. Faraday Discuss. 148, 269-282.

(42) Saysell, C. G., Murray, J. M., Wilmot, C. M., Brown, D. E., Dooley, D. M., Phillips, S. E. V., McPherson, M. J., and Knowles, P. F. (2000) Investigation into the mechanism of lambda(max) shifts and their dependence on $\mathrm{pH}$ for the 2-hydrazinopyridine derivatives of two copper amine oxidases. J. Mol. Catal. B: Enzym. 8, 17-25.

(43) Murray, J. M., Kurtis, C. R., Tambyrajah, W., Saysell, C. G., Wilmot, C. M., Parsons, M. R., Phillips, S. E., Knowles, P. F., and McPherson, M. J. (2001) Conserved tyrosine-369 in the active site of Escherichia coli copper amine oxidase is not essential. Biochemistry 40, 12808-12818.

(44) Shepard, E. M., Juda, G. A., Ling, K. Q., Sayre, L. M., and Dooley, D. M. (2004) Cyanide as a copper and quinone-directed inhibitor of amine oxidases from pea seedlings (Pisum sativum) and Arthrobacter globiformis: evidence for both copper coordination and cyanohydrin derivatization of the quinone cofactor. JBIC, J. Biol. Inorg. Chem. 9, 256-268.

(45) Kabsch, W. (2010) XDS. Acta Crystallogr., Sect. D: Biol. Crystallogr. 66, 125-132.

(46) Evans, J. P., Ahn, K., and Klinman, J. P. (2003) Evidence that dioxygen and substrate activation are tightly coupled in dopamine beta-monooxygenase. Implications for the reactive oxygen species. J. Biol. Chem. 278, 49691-49698.

(47) Potterton, E., Briggs, P., Turkenburg, M., and Dodson, E. (2003) A graphical user interface to the CCP4 program suite. Acta Crystallogr., Sect. D: Biol. Crystallogr. 59, 1131-1137.

(48) Murshudov, G. N., Vagin, A. A., and Dodson, E. J. (1997) Refinement of macromolecular structures by the maximum-likelihood method. Acta Crystallogr., Sect. D: Biol. Crystallogr. 53, 240-255.

(49) Emsley, P., and Cowtan, K. (2004) Coot: model-building tools for molecular graphics. Acta Crystallogr., Sect. D: Biol. Crystallogr. 60, $2126-2132$.

(50) Duff, A. P., Cohen, A. E., Ellis, P. J., Kuchar, J. A., Langley, D. B., Shepard, E. M., Dooley, D. M., Freeman, H. C., and Guss, J. M. (2003) The crystal structure of Pichia pastoris lysyl oxidase. Biochemistry 42, 15148-15157.

(51) Jakobsson, E., Nilsson, J., Ogg, D., and Kleywegt, G. J. (2005) Structure of human semicarbazide-sensitive amine oxidase/vascular adhesion protein-1. Acta Crystallogr., Sect. D: Biol. Crystallogr. 61, $1550-1562$.

(52) Li, R., Klinman, J. P., and Mathews, F. S. (1998) Copper amine oxidase from Hansenula polymorpha: the crystal structure determined at 2.4 A resolution reveals the active conformation. Structure 6, 293307.

(53) Lunelli, M., Di Paolo, M. L., Biadene, M., Calderone, V., Battistutta, R., Scarpa, M., Rigo, A., and Zanotti, G. (2005) Crystal structure of amine oxidase from bovine serum. J. Mol. Biol. 346, 9911004.

(54) McGrath, A. P., Mithieux, S. M., Collyer, C. A., Bakhuis, J. G., van den Berg, M., Sein, A., Heinz, A., Schmelzer, C., Weiss, A. S., and Guss, J. M. (2011) Structure and activity of Aspergillus nidulans copper amine oxidase. Biochemistry 50, 5718-5730.

(55) Parsons, M. R., Convery, M. A., Wilmot, C. M., Yadav, K. D., Blakeley, V., Corner, A. S., Phillips, S. E., McPherson, M. J., and Knowles, P. F. (1995) Crystal structure of a quinoenzyme: copper amine oxidase of Escherichia coli at 2 A resolution. Structure 3, 11711184.

(56) Wilce, M. C., Dooley, D. M., Freeman, H. C., Guss, J. M., Matsunami, H., McIntire, W. S., Ruggiero, C. E., Tanizawa, K., and Yamaguchi, H. (1997) Crystal structures of the copper-containing amine oxidase from Arthrobacter globiformis in the holo and apo forms: implications for the biogenesis of topaquinone. Biochemistry $36,16116-16133$.

(57) Gaule, T. G., Smith, M. A., Pearson, A. R., Knowles, P. F., and McPherson, M. J. (2015) Probing the molecular mechanisms in 
copper amine oxidases by generating heterodimers. ChemBioChem 16, $559-564$.

(58) Dove, J. E., Schwartz, B., Williams, N. K., and Klinman, J. P. (2000) Investigation of spectroscopic intermediates during copperbinding and TPQ formation in wild-type and active-site mutants of a copper-containing amine oxidase from yeast. Biochemistry 39, 36903698.

(59) Mure, M., Kurtis, C. R., Brown, D. E., Rogers, M. S., Tambyrajah, W. S., Saysell, C., Wilmot, C. M., Phillips, S. E., Knowles, P. F., Dooley, D. M., and McPherson, M. J. (2005) Active site rearrangement of the 2-hydrazinopyridine adduct in Escherichia coli amine oxidase to an azo copper(II) chelate form: a key role for tyrosine 369 in controlling the mobility of the TPQ-2HP adduct. Biochemistry 44, 1583-1594.

(60) Kishishita, S., Okajima, T., Kim, M., Yamaguchi, H., Hirota, S., Suzuki, S., Kuroda, S., Tanizawa, K., and Mure, M. (2003) Role of copper ion in bacterial copper amine oxidase: spectroscopic and crystallographic studies of metal-substituted enzymes. J. Am. Chem. Soc. 125, 1041-1055.

(61) Steinebach, V., deVries, S., and Duine, J. A. (1996) Intermediates in the catalytic cycle of copper-quinoprotein amine oxidase from Escherichia coli. J. Biol. Chem. 271, 5580-5588.

(62) Mills, S. A., Brown, D. E., Dang, K., Sommer, D., Bitsimis, A., Nguyen, J., and Dooley, D. M. (2012) Cobalt substitution supports an inner-sphere electron transfer mechanism for oxygen reduction in pea seedling amine oxidase. JBIC, J. Biol. Inorg. Chem. 17, 507-515.

(63) Mills, S. A., Goto, Y., Su, Q., Plastino, J., and Klinman, J. P. (2002) Mechanistic comparison of the cobalt-substituted and wildtype copper amine oxidase from Hansenula polymorpha. Biochemistry 41, 10577-10584.

(64) Stellato, F., Oberthur, D., Liang, M. N., Bean, R., Gati, C., Yefanov, O., Barty, A., Burkhardt, A., Fischer, P., Galli, L., Kirian, R. A., Meyer, J., Panneerselvam, S., Yoon, C. H., Chervinskii, F., Speller, E., White, T. A., Betzel, C., Meents, A., and Chapman, H. N. (2014) Room-temperature macromolecular serial crystallography using synchrotron radiation. IUCrJ 1, 204-212.

(65) Klema, V. J., Johnson, B. J., Klinman, J. P., and Wilmot, C. M. (2012) The precursor form of Hansenula polymorpha copper amine oxidase 1 in complex with $\mathrm{Cu}-\mathrm{II}$ and Co-II. Acta Crystallogr., Sect. F: Struct. Biol. Cryst. Commun. 68, 501-510.

(66) Okajima, T., Kishishita, S., Chiu, Y. C., Murakawa, T., Kim, M., Yamaguchi, H., Hirota, S., Kuroda, S., and Tanizawa, K. (2005) Reinvestigation of metal ion specificity for quinone cofactor biogenesis in bacterial copper amine oxidase. Biochemistry 44, 12041-12048.

(67) Chen, Z., Schwartz, B., Williams, N. K., Li, R., Klinman, J. P., and Mathews, F. S. (2000) Crystal structure at $2.5 \mathrm{~A}$ resolution of zinc-substituted copper amine oxidase of Hansenula polymorpha expressed in Escherichia coli. Biochemistry 39, 9709-9717.

(68) Prabhakar, R., and Siegbahn, P. E. M. (2004) A theoretical study of the mechanism for the biogenesis of cofactor topaquinone in copper amine oxidases. J. Am. Chem. Soc. 126, 3996-4006.

(69) Baron, R., McCammon, J. A., and Mattevi, A. (2009) The oxygen-binding vs. oxygen-consuming paradigm in biocatalysis: structural biology and biomolecular simulation. Curr. Opin. Struct. Biol. 19, 672-679.

(70) Mure, M., Brown, D. E., Saysell, C., Rogers, M. S., Wilmot, C. M., Kurtis, C. R., McPherson, M. J., Phillips, S. E., Knowles, P. F., and Dooley, D. M. (2005) Role of the interactions between the active site base and the substrate Schiff base in amine oxidase catalysis. Evidence from structural and spectroscopic studies of the 2-hydrazinopyridine adduct of Escherichia coli amine oxidase. Biochemistry 44, 1568-1582.

(71) Medda, R., Padiglia, A., Bellelli, A., Sarti, P., Santanche, S., Finazzi Agrò, A. F., and Floris, G. (1998) Intermediates in the catalytic cycle of lentil (Lens esculenta) seedling copper-containing amine oxidase. Biochem. J. 332, 431-437.

(72) Padiglia, A., Medda, R., Pedersen, J. Z., Finazzi Agrò, A. F., Lorrai, A., Murgia, B., and Floris, G. (1999) Effect of metal substitution in copper amine oxidase from lentil seedlings. JBIC, J. Biol. Inorg. Chem. 4, 608-613.

(73) Schwartz, B., Dove, J. E., and Klinman, J. P. (2000) Kinetic analysis of oxygen utilization during cofactor biogenesis in a coppercontaining amine oxidase from yeast. Biochemistry 39, 3699-3707. 